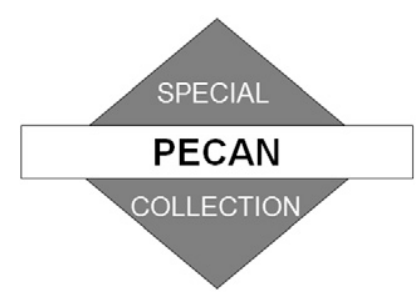

\title{
Evolution of Pre- and Postconvective Environmental Profiles from Mesoscale Convective Systems during PECAN
}

\author{
STACEy M. HitchCOCK, Russ S. SCHUMACHER, AND GREGORY R. HERMAN \\ Department of Atmospheric Science, Colorado State University, Fort Collins, Colorado \\ Michael C. CONIGLiO \\ NOAA/OAR/National Severe Storms Laboratory, Norman, Oklahoma \\ MATTHEW D. PARKER \\ Department of Marine, Earth, and Atmospheric Sciences, North Carolina State University, \\ Raleigh, North Carolina \\ CONRAD L. ZIEGLER \\ NOAA/OAR/National Severe Storms Laboratory, Norman, Oklahoma
}

(Manuscript received 5 July 2018, in final form 1 April 2019)

\begin{abstract}
During the Plains Elevated Convection at Night (PECAN) field campaign, 15 mesoscale convective system (MCS) environments were sampled by an array of instruments including radiosondes launched by three mobile sounding teams. Additional soundings were collected by fixed and mobile PECAN integrated sounding array (PISA) groups for a number of cases. Cluster analysis of observed vertical profiles established three primary preconvective categories: 1) those with an elevated maximum in equivalent potential temperature below a layer of potential instability; 2) those that maintain a daytime-like planetary boundary layer (PBL) and nearly potentially neutral low levels, sometimes even well after sunset despite the existence of a southerly low-level wind maximum; and 3) those that are potentially neutral at low levels, but have very weak or no southerly low-level winds. Profiles of equivalent potential temperature in elevated instability cases tend to evolve rapidly in time, while cases in the potentially neutral categories do not. Analysis of composite Rapid Refresh (RAP) environments indicate greater moisture content and moisture advection in an elevated layer in the elevated instability cases than in their potentially neutral counterparts. Postconvective soundings demonstrate significantly more variability, but cold pools were observed in nearly every PECAN MCS case. Following convection, perturbations range between -1.9 and $-9.1 \mathrm{~K}$ over depths between $150 \mathrm{~m}$ and $4.35 \mathrm{~km}$, but stronger, deeper stable layers lead to structures where the largest cold pool temperature perturbation is observed above the surface.
\end{abstract}

\section{Introduction}

Mesoscale convective systems (MCSs) play a critical role in the warm season nocturnal precipitation maximum over the U.S. Great Plains region (e.g., Wallace 1975; Maddox 1980; Fritsch et al. 1986; Carbone et al. 2002). These systems provide essential rainfall, but are often associated with severe weather (Jirak et al. 2003;

Corresponding author: Stacey M. Hitchcock, smhitch@ rams.colostate.edu
Maddox 1980). Despite its frequency and importance, nocturnal convection is not particularly well forecast in numerical models (Davis et al. 2003; Clark et al. 2007; Johnson and Wang 2013; Johnson et al. 2013).

MCSs span a distance of $\sim 100 \mathrm{~km}$ or larger and can have a variety of organizational modes (Parker and Johnson 2000; Houze 2004; Schumacher and Johnson 2005). They are often associated with a midlevel shortwave trough, a baroclinic zone (in the United States this is often a warm or stationary surface front), a statically stable boundary layer, a low-level jet (LLJ), 
and the associated advection of warm, moist, high $\theta_{e}$ air in an elevated layer (Maddox 1983; Trier and Parsons 1993; Augustine and Caracena 1994; Laing and Fritsch 2000; Moore et al. 2003; Peters and Schumacher 2014). Because of the nocturnal nature of many MCSs, the inflow layer is often thought to be primarily elevated (e.g., Moore et al. 2003; Corfidi et al. 2008; Geerts et al. 2017). While a number of definitions of "elevated" exist throughout the literature, in the rest of this paper an elevated MCS refers to an MCS that does not ingest air from the near-surface layer (i.e., is decoupled), consistent with definitions in Parker (2008), French and Parker (2010), Billings and Parker (2012), and the Glossary of Meteorology Glickman (2000). However, just because an environment might have elevated instability, does not mean that the resulting MCS was necessarily elevated.

In a study of a nocturnal mesoscale convective complex (MCC) during PRE-STORM (Cunning 1986), large increases in $\theta_{e}$ were observed in an elevated layer between 0200 and 0500 UTC (Trier and Parsons 1993). Changes were associated with the southward progression of a shallow surface front, and an increase in moisture advection in conjunction with the onset of the southerly nocturnal LLJ. These observations led to a schematic (Fig. 20 in Trier and Parsons 1993) of isentropic ascent of high $\theta_{e}$ air associated with the LLJ over a quasi-stationary frontal zone. This has become a relatively common conceptual model for nocturnal MCS environments (e.g., Fritsch and Forbes 2001; Moore et al. 2003; Trier et al. 2006).

An increase in $\theta_{e}$ with time can also lead to a large increase in potential instability over an elevated layer and in the convective available potential energy (CAPE) of inflow parcels, particularly that of the most unstable parcels. Potential instability (convective instability) occurs when the equivalent potential temperature $\theta_{e}$ of the environment decreases with height [ $\left(d \theta_{e} / d z\right)<0$; Rossby 1932; Hewson 1937]. This elevated instability serves as a critical source of inflow air to storms located on the cool side of a frontal boundary (Trier et al. 2006), or above a nocturnal stable layer (Parker 2008) and is related to layer lifting, a process considered critical in the development of nocturnal deep convection (Moncrieff 1992; Bryan and Fritsch 2000; Houze 2004; Alfaro and Coniglio 2018).

Nocturnal convection is usually associated with a statically stable boundary layer [see Schultz et al. (2000) for an in-depth review of instabilities] brought about by nocturnal cooling (e.g., Trier and Parsons 1993; Corfidi et al. 2008; Parker 2008; Geerts et al. 2017) or with MCS initiation on the cool side of a quasi-stationary or warm front (e.g., Maddox et al.
1978; Trier and Parsons 1993; Corfidi et al. 2008; Peters and Schumacher 2014). Past studies have suggested that depending on the strength of convective downdrafts (e.g., Trier and Parsons 1993; Marsham et al. 2010), the amount of low-level cooling (e.g., Parker 2008), and more recently the curvature of the wind shear (Haghi et al. 2017), that MCS outflow may manifest as surface cold pools (e.g., Trier et al. 2006; Parker 2008; Peters and Schumacher 2015), bores (e.g., Crook 1988; Wilson and Roberts 2006; Haghi et al. 2017), gravity waves (Crook and Moncrieff 1988; Parker 2008; Schumacher 2009; Marsham et al. 2010) or other combinations of gravity waves and gravity currents (e.g., Raymond and Rotunno 1989; Haertel et al. 2001). There is additional evidence that with changing conditions, MCSs may also transition from one driving mechanism to another (Parker 2008; Trier et al. 2011). Despite previous understanding that in the presence of a stable layer, the primary inflow is decoupled from the surface, more recent work has shown that some MCSs may continue to ingest stable boundary layer air, even after significant cooling has occurred (Davis et al. 2004; Parker 2008; French and Parker 2008; Billings and Parker 2012). The interaction of convection with a stable boundary layer is not well understood, yet their relationship plays a key role in determining the propagation and maintenance of nocturnal MCSs.

A number of field campaigns have used relatively closely spaced, high-frequency radiosonde launches from fixed and mobile assets to learn about convection and convective environments in the Great Plains [e.g., PRE-STORM, Cunning (1986); BAMEX, Davis et al. (2004); VORTEX2, Wurman et al. (2012); MPEX, Weisman et al. (2015)]. In a manner similar to the present study, Correia and Arritt (2008) used dropsonde observations from the Bow Echo and MCV Experiment (BAMEX) to construct composite soundings of seven distinct MCS subregions. Their study placed a greater emphasis on spatiotemporal variability than case-to-case variability, and had a notable focus on transition and stratiform regions. Their results note similar preconvective environments to previously mentioned studies and large thermodynamic variability in transition and stratiform regions below $0^{\circ} \mathrm{C}$. Over the years, technological improvements have allowed us to observe with higher frequency. This, combined with different sampling strategies, has improved our ability to observe smaller-scale changes in the convective environment.

During the 2015 Plains Elevated Convection at Night (PECAN) field experiment, a vast array of instruments were deployed by a multitude of research groups to observe a number of phenomena related to nocturnal convection, including nocturnal MCSs, in order to work 
TABLE 1. Selected cases, region of intensive observation, and platforms available in identified region. FP is the abbreviation used for the fixed PECAN integrated sounding arrays (PISAs). MP is the abbreviation used for the mobile PISAs, which were generally mobile before, but stationary during IOPs. MG is the abbreviation used for the highly mobile GPS radiosonde launch vehicles.

\begin{tabular}{|c|c|c|c|c|}
\hline Date & Region & Available platforms & Preconvective soundings & Postconvective soundings \\
\hline 11 Jun & Southeast NE & MGs, FP3-FP6, MPs & 8 & 14 \\
\hline 12 Jun & Southwest KS & MGs, FP1-FP3, FP5, MPs & 16 & 21 \\
\hline 15 Jun & South-central KS & MGs, FP1, FP2, FP6, MPs & 11 & 7 \\
\hline 17 Jun & Southwest NE & MGs, FP3-FP5, MPs & 23 & 12 \\
\hline 25 Jun & Southeast IA & MGs, MP3, MP4 & 18 & 8 \\
\hline 26 Jun & Northeast KS & MGs, FP2-FP6, MPs & 28 & 16 \\
\hline $1 \mathrm{Jul}$ & Northwest MO & MGs, FP4, MPs & 19 & 21 \\
\hline $2 \mathrm{Jul}$ & West MO & MG1, MG2, MP1 & 7 & 2 \\
\hline $6 \mathrm{Jul}$ & SD & MGs, FP4, FP5, MPs & 19 & 7 \\
\hline $9 \mathrm{Jul}$ & TX Panhandle & MGs & 9 & 9 \\
\hline $10 \mathrm{Jul}$ & TX Panhandle & MGs, FP2 & 19 & 2 \\
\hline $11 \mathrm{Jul}$ & KS-NE border & MGs, FPs, MP2-MP4 & 39 & 0 \\
\hline $13 \mathrm{Jul}$ & Southeast MN & MGs, MP1 & 26 & 4 \\
\hline $14 \mathrm{Jul}$ & West IN & MGs, MP1 & 5 & 6 \\
\hline $16 \mathrm{Jul}$ & Southeast NE & MGs, FP2-FP6, MPs & 48 & 20 \\
\hline Total & & & 295 & 149 \\
\hline
\end{tabular}

toward improving the low predictive skill of their forecasts. PECAN was the first of its magnitude to explicitly focus on nocturnal environments (Geerts et al. 2017). During the campaign, missions or intensive observing periods (IOPs) were conducted to observe convective initiation (CI), bores, MCSs, and the LLJ. During each of these IOPs, numerous observations were collected from both fixed and mobile platforms. The work presented here focuses on documenting and analyzing the radiosonde observations collected in MCS environments from all platforms. For a more detailed description of PECAN goals, assets, and deployments see Geerts et al. (2017).

While some previous field experiments have observed nocturnal MCS environments, much of the prior analysis has focused on individual cases (e.g., Trier and Parsons 1993; Trier et al. 2011) or various types/regions of MCS environments without distinction between day and night (e.g., Correia and Arritt 2008; Peters and Schumacher 2014). Furthermore, the mechanisms for maintaining nocturnal MCSs are not fully understood. This is due in part to the lack of detailed observations of the nocturnal boundary layer. The PECAN radiosonde dataset presents a unique opportunity to analyze a wealth of observations of vertical characteristics of the atmosphere previously unseen. The goals of this paper are to address the questions: 1) What are the defining thermodynamic characteristics of the preconvective nocturnal MCS environments sampled? 2) How do these observed MCS environments fit with the common conceptual model? 3) What are the thermodynamic characteristics of sampled postconvective environments? More specifically, how frequently are cold pools observed? How strong/deep/variable are they? This work applies a cluster analysis to the rich dataset of nocturnal MCS soundings collected during PECAN to explore the different preconvective MCS environments observed. Next, temperature perturbations observed in postconvective regions are compared between cases, and related to preconvective stability.

\section{Overview of mesoscale convective system cases during PECAN}

Thirteen MCS cases and two bore cases from PECAN with observations of MCS environments were selected for this study. One MCS IOP and three aircraft-only MCS unofficial field operations ("UFOs") were not included in this study due to a missed deployment (storms developed north of the array and propagated north) and lack of radiosonde observations, respectively. A list of cases used ${ }^{1}$ and the region where they were observed can be found in Table 1. For the purposes of this study, preconvective refers to the environment ahead of an MCS gust front, rather than environment prior to convective initiation. More specific details about the delimitation between pre- and postconvective environments will be discussed in section 3 .

Figure 1 shows fields from the 0000 UTC Rapid Refresh (RAP) analysis (Benjamin et al. 2016) for each

\footnotetext{
${ }^{1}$ Nighttime events often begin on one day and end the next. Cases are referred to by the date on which the majority of observations actually took place in UTC.
} 

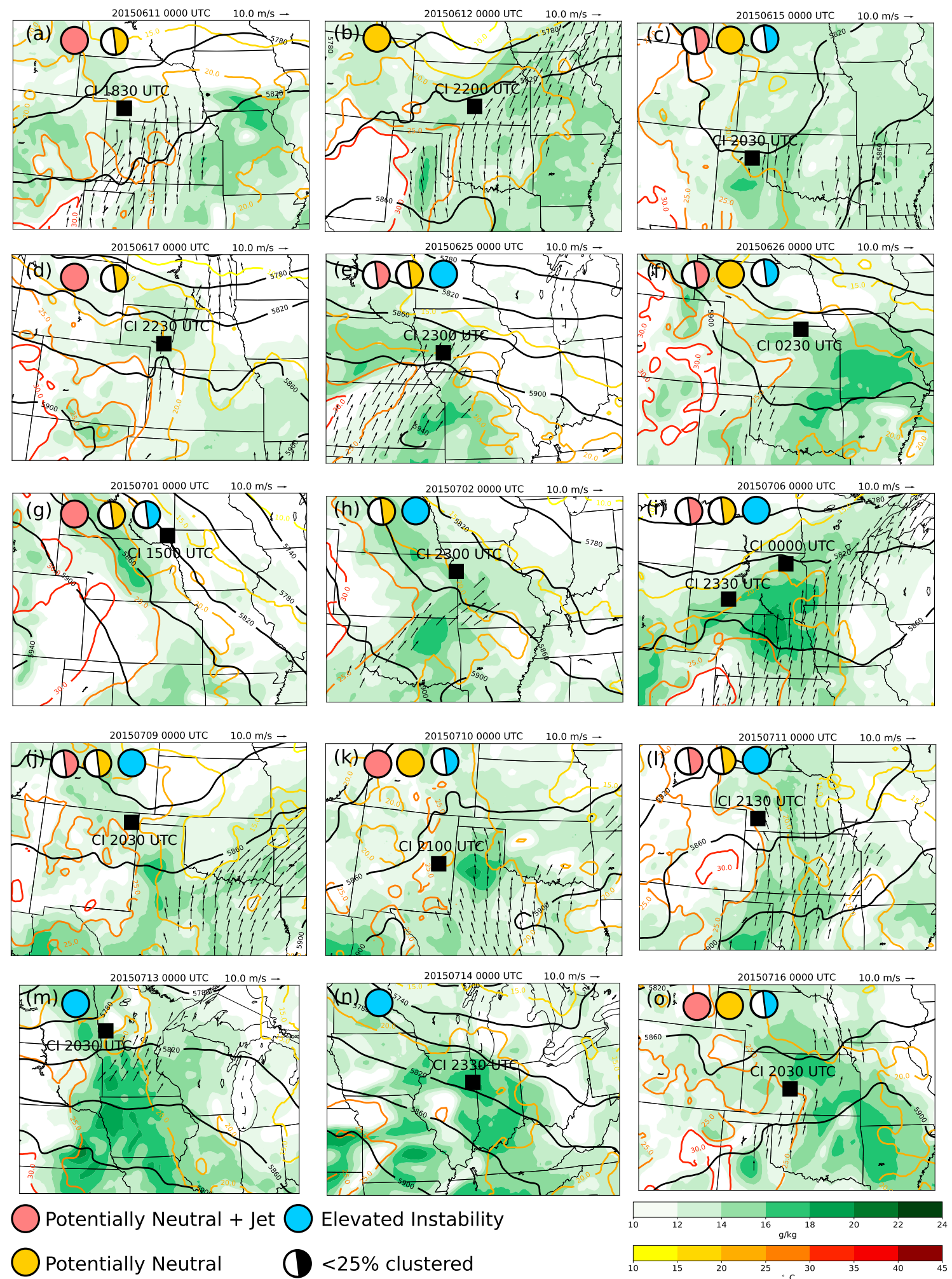

FIG. 1. The 0000 UTC Rapid Refresh (RAP) analysis for each case. 500-hPa heights (m; black contour), 850-hPa wind vectors where $\mathbf{v}>10 \mathrm{~m} \mathrm{~s}^{-1}, 850-\mathrm{hPa}$ temperature $\left({ }^{\circ} \mathrm{C}\right.$; color contours), and 850 -hPa mixing ratios $\left(\mathrm{g} \mathrm{kg}^{-1}\right.$; green filled). Colored dots represent clusters in which soundings were grouped. Half shaded circles indicate $<25 \%$ of soundings from the case were in the cluster. The black square(s) in each panel indicates the approximate location where convection that grew upscale into the observed MCS initiated, and is accompanied by an approximate time of initiation. 
case. In nearly every case, convection initiated prior to 0000 UTC (before dark), and usually several hours before PECAN teams observed the subsequent MCS. ${ }^{2}$ For this reason, panels are centered on the approximate location of the IOP target region. Cases are generally associated with a $\mathrm{N}-\mathrm{S}$ temperature gradient, predominately westerly upper-level flow, and $850-\mathrm{hPa}^{3}$ RAP-analyzed southerly winds in the target region. There are, however, differences in the orientation of the surface front and the 500-hPa heights, coverage of the $850-\mathrm{hPa}$ southerly winds, and the existence of an upper-level wind maximum from case to case. Note that a 0000 UTC analysis may not provide an accurate depiction of the LLJ strength for a particular case, since the LLJ typically develops after sunset, which occurs around 0200 UTC over much of the Great Plains at this time of year. A more detailed analysis based on composites of observed MCS environments and a more detailed case analysis for representative cases is discussed in section $4 \mathrm{~d}$.

IOPs sampled a range of MCS structures from a wellorganized, progressive bow echo with a trailing stratiform region on 13 July in MN (Fig. 2m), to MCSs with quasi-stationary or training cells (Figs. 2e,j), and many more loosely organized cases with various structures such as those of 26 June and 16 July (Figs. 2f,o). In some cases, observations primarily captured weakly organized early convection and upscale growth (e.g., Fig. 2d). In others, observations captured the weakening of a convective line, as convective cells transitioned to stratiform precipitation (e.g., Fig. 2k). In one case, 14 July, an MCS only formed to the south and east of the target location well after the IOP ended. It was still included here given the favorable MCS environment and forecast.

\section{Methods}

\section{a. Dataset}

Radiosondes were launched from a number of fixed and mobile sites throughout PECAN. A list of those used in this work is given in Table 2. Radiosonde data used were quality controlled (QC'd) by NCAR's Earth Observing Laboratory and postprocessed by Aspen software (see https://www.eol.ucar.edu/software/aspen).

\footnotetext{
${ }^{2}$ On 26 June, there was some convection in the region prior to 0000 UTC, but the primary MCS observed initiated around 0230 UTC. On 6 July, PECAN teams observed two MCSs that converged, so two CI locations are noted.

${ }^{3}$ An $850-\mathrm{hPa}$ analysis was selected because while it may be too high for an accurate depiction of the LLJ in some observed cases, a 925-hPa analysis is below ground in others.
}

The six FPs (defined in Table 1) were located in Kansas, Nebraska, and Oklahoma. During MCS missions, these sites often launched radiosondes every $3 \mathrm{~h}$ beginning at 0000 UTC. Sometimes, the FP sites did additional launches during the day to aid in forecasting efforts. The four MPs (defined in Table 1) also had the capability to launch soundings, and when they participated in MCS IOPs, ${ }^{4}$ they typically launched radiosondes every 1-3 h. In some cases, MP or FP sites were located well away from the target MCS location and were unrepresentative of the target MCS environment and thus not included. It should also be noted that the PECAN domain is not completely flat, which is accounted for in the composite analysis, and should not influence the fundamental conclusions of this work.

While MPs were stationary during an IOP, MGs (defined in Table 1) were highly mobile. The MGs' primary responsibility was to launch radiosondes with high-temporal/spatial frequency throughout the duration of the IOP. Two main sampling strategies were used for the MGs. In one, teams were staggered parallel to the convective line and would reposition after its passage to sample along-line spatial heterogeneities (as in 11 June); in the other, teams were collocated and did "rapid-fire" launches at 15-20-min intervals to sample the rapid temporal changes as the convection approached. The latter method tended to be preferred as the project progressed. Where appropriate, standard NWS soundings were used to supplement the dataset. In the 15 MCS cases used (Table 1), a relatively large number of radiosondes sampled an MCS environment during at least one stage of its life cycle leading to a total of 295 preconvective and 149 postconvective soundings. Additional details about PECAN radiosonde observations in MCS environments can be found in appendix A.

\section{b. Cluster analysis}

During early analysis, it became clear that potential (in)stability $\left(d \theta_{e} / d z\right)$ varied widely from case to case, but different cases appeared to have some common features at low levels. To objectively search for patterns to categorize the preconvective soundings, a cluster analysis was used. The vertical gradient in equivalent potential temperature $\left(\theta_{e}\right)$ and both ground-relative wind components $(u, v)$ were chosen as the variables used to

\footnotetext{
${ }^{4}$ Toward the end of the project, there were some split missions, and some MCS IOPs took place outside of the originally defined PECAN domain. The MPs did not always accompany the MCS IOP but when they did, they provided valuable additional radiosonde data.
} 

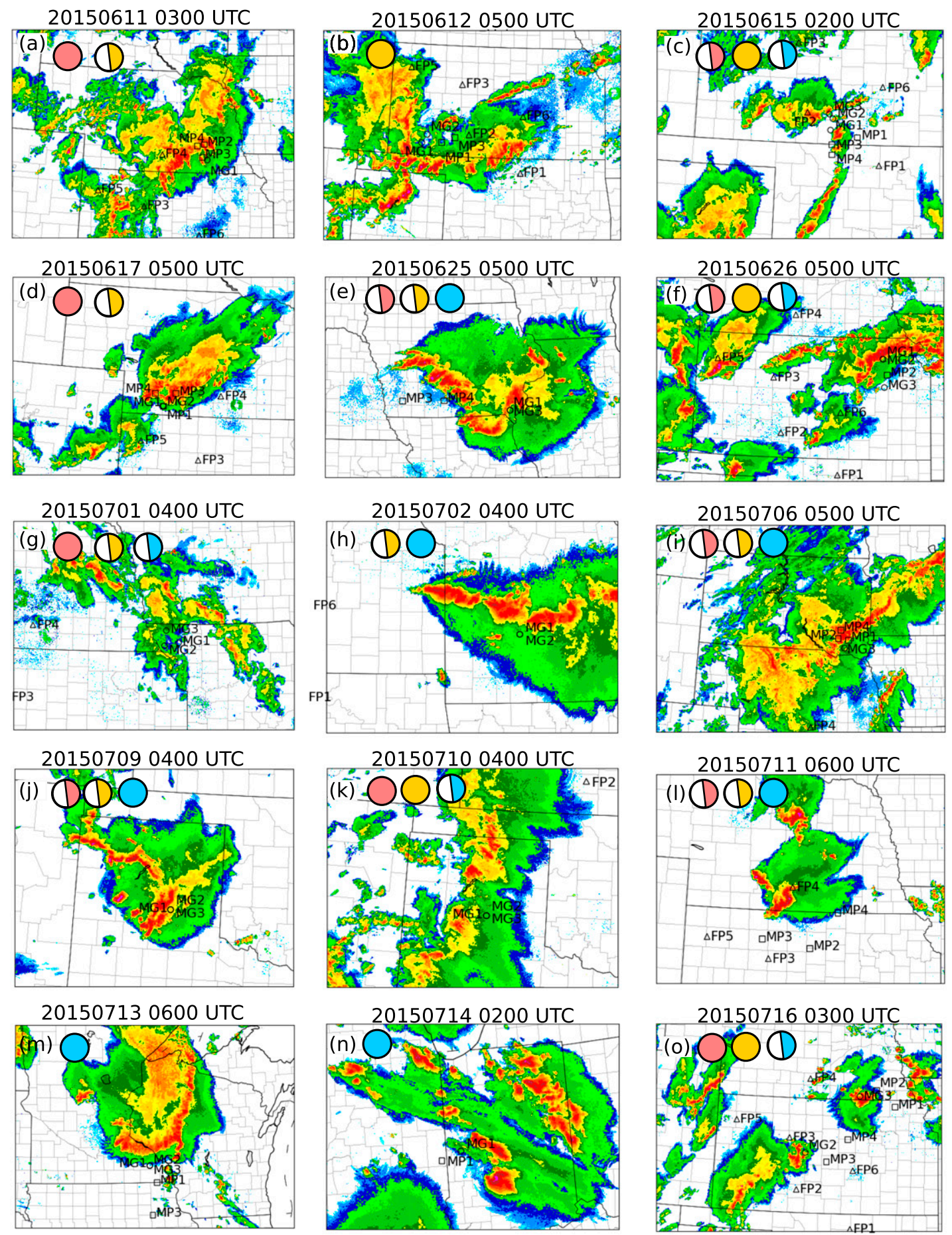
Potentially Neutral + Jet
Elevated Instability
Potentially Neutral
$<25 \%$ clustered

FIG. 2. Radar reflectivity from the NSSL Multi-Radar Multi-Sensor (MRMS) system (Zhang et al. 2016) of observed convection during each IOP and positions of mobile assets at (a) 0300 UTC 11 Jun, (b) 0500 UTC 12 Jun, (c) 0200 UTC 15 Jun, (d) 0500 UTC 17 Jun, (e) 0500 UTC 25 Jun, (f) 0500 UTC 26 Jun, (g) 0400 UTC 1 Jul, (h) 0400 UTC 2 Jul, (i) 0500 UTC 6 Jul, (j) 0400 UTC 9 Jul, (k) 0400 UTC $10 \mathrm{Jul}$, (1) $0600 \mathrm{UTC} 11 \mathrm{Jul}$, (m) 0600 UTC $13 \mathrm{Jul}$, (n) 0200 UTC $14 \mathrm{Jul}$, and (o) 0300 UTC 16 Jul. Colored dots represent case sounding clusters as in Fig. 1. Open circle, square, and triangle symbols are used for MG, MP, and FP assets, respectively. 
TABLE 2. Sources of radiosonde data included in this study.

\begin{tabular}{llll}
\hline \hline Platform & \multicolumn{1}{c}{ Location } & \multicolumn{1}{c}{ Radiosonde type } & \multicolumn{1}{c}{ Citation } \\
\hline MGs & Mobile & Vaisala RS-92 & Ziegler et al. (2016) \\
FP1 & Lamont, OK & Vaisala RS-92 & UCAR/NCAR-Earth Observing Laboratory (2015) \\
FP2 & Greensburg, KS & iMet-1 & Vermeesch (2016) \\
FP3 & Ellis, KS & Vaisala RS-92 & Clark (2016) \\
FP4 & Minden, NE & Vaisala RS-92 & UCAR/NCAR-Earth Observing Laboratory (2016b) \\
FP5 & Brewster, KS & Vaisala RS-92 & UCAR/NCAR-Earth Observing Laboratory (2016c) \\
FP6 & Hesston, KS & Vaisala RS-92 & Holdridge and Turner (2015) \\
MP1 & Mobile & iMet-1 & Klein et al. (2016) \\
MP2 & Mobile & iMet-1 & Knupp (2015) \\
MP3 & Mobile & Vaisala RS-92 & Wagner et al. (2016) \\
MP4 & Mobile & Vaisala RS-92 & UCAR/NCAR-Earth Observing Laboratory (2016d) \\
NWS & Relevant & Lockheed Martin & UCAR/NCAR-Earth Observing Laboratory (2016a) \\
& & LMS-6/Vaisala RS-92 & \\
\hline
\end{tabular}

identify clusters; $\theta_{e}$ is a function of both temperature and moisture and as mentioned previously, its vertical gradient is related to the potential (in)stability of a layer. Changes in zonal and meridional wind components can be used to determine the location and existence of a nocturnal low-level wind maximum, and were included for this reason. Profiles of $\theta_{e}$, $u$, and $v$ were interpolated to a $25-\mathrm{m}$ vertical grid, and smoothed using a Gaussian smoother $(\sigma=100,50$, $50 \mathrm{~m}$ respectively) to reduce noise but preserve structure. Soundings that did not reach $3 \mathrm{~km}$ in altitude were not included in this analysis, and analysis was only performed on the lowest $3 \mathrm{~km}$ of all remaining soundings. Changes in the selected variables with height $\left(d \theta_{e} / d z, d u / d z\right.$, and $\left.d v / d z\right)$ were computed and then standardized, using a global standard to maintain profile shape, so that they could be compared across cases. Principal component analysis (PCA) is commonly employed to reduce dimensionality in large datasets containing highly correlated variables (Herman and Schumacher 2018). PCA was applied here and three principal components were retained. Additional details about the PCA and related decisions can be found in appendix B.

To focus on understanding differences within pre- and postconvective environments themselves, pre- and postconvective environments were first sorted manually based on the profiles of $\theta_{v}, \theta_{e}$, wind, and the launch location relative to radar fine lines (where applicable). For the purposes of this analysis, a "preconvective" sounding is one that was taken prior to the observation of a cold pool produced by the observed MCS at a particular location. Therefore, a "postconvective" sounding, for this purpose, is one that has been modified at low levels by the outflow produced by the observed MCS. The number of pre- and postconvective soundings that made it to $3 \mathrm{~km}$ is listed in Table 1 by case.
A cluster analysis is a method of objectively grouping a set of objects based on shared characteristics. Different clustering algorithms have different advantages and disadvantages. The Shared Nearest Neighbors (SSN) method was selected for this application because unlike other methods, it handles variable density clusters, does not require the number of clusters to be specified in advance, and does not force every point into a cluster (i.e., outliers are not forced into ill-fitting clusters). Scatterplots of PCs against each other showed that the preconvective environmental sounding dataset has both variable densities, and a number of outliers (not shown). Clusters produced by the SSN method were broadly similar to clusters produced by DBSCAN (Ester et al. 1996) and $K$-means methods, but without the same limitations. Since the clustering method itself is not the focus of this work, more specific details about it can be found in appendix B.

Composite soundings for each cluster were generated using the technique described in Trier et al. (2000), where rather than truncating or extrapolating soundings to a common surface elevation, radiosonde data are interpolated to a normalized sigma $\left(\sigma=p / p_{s}\right)$ coordinate. Advantages of this method are its intention to preserve boundary layer structure and conserve the mean CAPE and CIN of the soundings used to create the composite. Levels are chosen such that $\Delta \sigma=0.01$ at lower levels (below $\sigma=0.8$ ) and 0.02 aloft (Trier et al. 2000). The mean pressure at $\sigma=1$ for each cluster was used to compute the pressure at each sigma level in each cluster. The composites presented here were computed by taking a strict average of all soundings in each cluster, but compositing first on the mean of each case does not change results substantially. The mean surface pressure for each cluster was used to back out the pressure coordinates for composite soundings. 
TABLE 3. Number of soundings clustered for each case in each cluster. An asterisk denotes that at least $25 \%$ of soundings from the given case were clustered.

\begin{tabular}{lcccc}
\hline \hline Date & $\begin{array}{c}\text { Preconvective } \\
\text { soundings }\end{array}$ & $\begin{array}{c}\text { Potentially } \\
\text { neutral + jet }\end{array}$ & $\begin{array}{c}\text { Potentially } \\
\text { neutral }\end{array}$ & $\begin{array}{c}\text { Elevated } \\
\text { instability }\end{array}$ \\
\hline 11 Jun & 8 & $7^{*}$ & 1 & 0 \\
12 Jun & 16 & 0 & $15^{*}$ & 0 \\
15 Jun & 11 & 1 & $9^{*}$ & 1 \\
17 Jun & 23 & $22^{*}$ & 1 & 0 \\
25 Jun & 18 & 4 & 1 & $7^{*}$ \\
26 Jun & 28 & 4 & $11^{*}$ & 4 \\
1 Jul & 19 & $6^{*}$ & 2 & 2 \\
2 Jul & 7 & 0 & 1 & $6^{*}$ \\
6 Jul & 19 & 1 & 2 & $12^{*}$ \\
9 Jul & 9 & 2 & 2 & $5^{*}$ \\
10 Jul & 19 & $6^{*}$ & $7 *$ & 4 \\
11 Jul & 39 & 5 & 4 & $28^{*}$ \\
13 Jul & 26 & 0 & 0 & $25^{*}$ \\
14 Jul & 5 & 0 & 0 & $2^{*}$ \\
16 Jul & 48 & $19^{*}$ & $21^{*}$ & 2 \\
Total & 295 & 77 & 77 & 98 \\
\hline
\end{tabular}

\section{Cluster analysis results on environment soundings}

The cluster analysis sorted 252 of the 295 soundings into three distinct clusters. The first cluster, made up of 77 profiles from five primary cases (see Table 3 for individual cluster breakdowns), is approximately potentially neutral (constant $\theta_{e}$ with height) in the lowest $2.5 \mathrm{~km}$ (Fig. 3a), and has evidence of a $10-20 \mathrm{~m} \mathrm{~s}^{-1}$ lowlevel southerly wind maximum below $500 \mathrm{~m}$ (Fig. 3b). For this reason, this cluster will be referred to as "potentially neutral + jet." This cluster also has a slight maximum in easterly winds in the lowest $250 \mathrm{~m}$ (Fig. 3b). Some of the clustered soundings, especially those from 16 July and 10 July, are even potentially unstable at low levels. At the same time, those same cases (and most other profiles in this cluster) have low-level static stability (Fig. 4a).

The second cluster is made up of 79 profiles, primarily from 5 different cases (Fig. 3d, Table 3). This cluster is also potentially neutral at low levels, but becomes potentially unstable between 1 and $1.5 \mathrm{~km}$ (Fig. 3d). Unlike the previous cluster, most of the profiles in this cluster have little-to-no static stability near the surface (Fig. 4b). Perhaps the greatest difference between this cluster and the first is that lowlevel winds are either considerably weaker southerlies, or even northerly (Fig. 3e). This cluster will be referred to as "potentially neutral." This cluster also has a deeper layer with an easterly wind component.

The third cluster is made up of 98 profiles from 7 primary cases, most notably the 6 July, 11 July, and 13 July events (Fig. 3g). The cluster name "elevated instability" was selected because 1) the most unstable parcel for profiles in this category is clearly elevated ( $\theta_{e}$ maximized above the surface) and 2) A deep region of potential instability can be found extending from the point of maximum $\theta_{e}$. This $\theta_{e}$ maximum occurs at slightly different altitudes, between just below 0.5 and $1 \mathrm{~km}$, in the dominant cases. Below the elevated $\theta_{e}$ maximum, the profiles are potentially stable, while above, they are potentially unstable. As stated previously, just because the most unstable parcel in these environments is elevated, does not mean that the MCSs themselves are elevated. A few of the profiles have a slight easterly wind component near the surface that maximizes at or below $250 \mathrm{~m}$ (Fig. 3h). Above that, winds shift to more westerly just above $500 \mathrm{~m}$. Some of the profiles do not have a near-surface easterly component, and rather have nearly no zonal component ( $<5 \mathrm{~m} \mathrm{~s}^{-1}$ either direction; Fig. 3h). In this cluster, southerly winds increased between 10 and $15 \mathrm{~m} \mathrm{~s}^{-1}$ over the lowest $500 \mathrm{~m}$ (Fig. 3h). The magnitude of southerly low-level winds observed in this cluster are only slightly larger (on average) than those observed in the potentially neutral + jet cluster, yet there is a substantial difference in the associated $\theta_{e}$ profiles. This cluster also has a deeper and stronger layer of near-surface static stability than either of the other clusters (Fig. 4c).

Histograms of the launch times of clustered soundings indicate that soundings in the two potentially neutral clusters tended to be launched earlier in the evening than those in the elevated instability cluster (Figs. 3c,f). Admittedly, the potentially neutral cluster without the strong low-level wind maximum has more daytime-like environmental characteristics, and early soundings from many of the cases ended up in this category. However, a nonnegligible number of soundings in the potentially neutral, no-jet cluster were launched well after dark, especially during the 12 June and 26 June cases. The vast majority of the soundings in the potentially neutral + jet cluster were still launched after sunset $(\sim 0200$ UTC). The addition of a single case, 11 July, in which the primary MCS observations took place much later than the majority of other observed cases nearly doubles the number of launches after 0600 UTC in the elevated instability cluster. When the same cluster analysis was run on soundings launched after 0200 UTC, and even after 0400 UTC, the same basic clusters emerge.

\section{a. Distribution of cluster convective parameters}

A violin plot, similar to a box plot, displays the mean (magenta line), median, and the probability density of the cluster at different values (shaded). Violin plots of convective parameters computed from soundings that make up the clusters give an idea of the distribution of 
Potentially Neutral + Jet
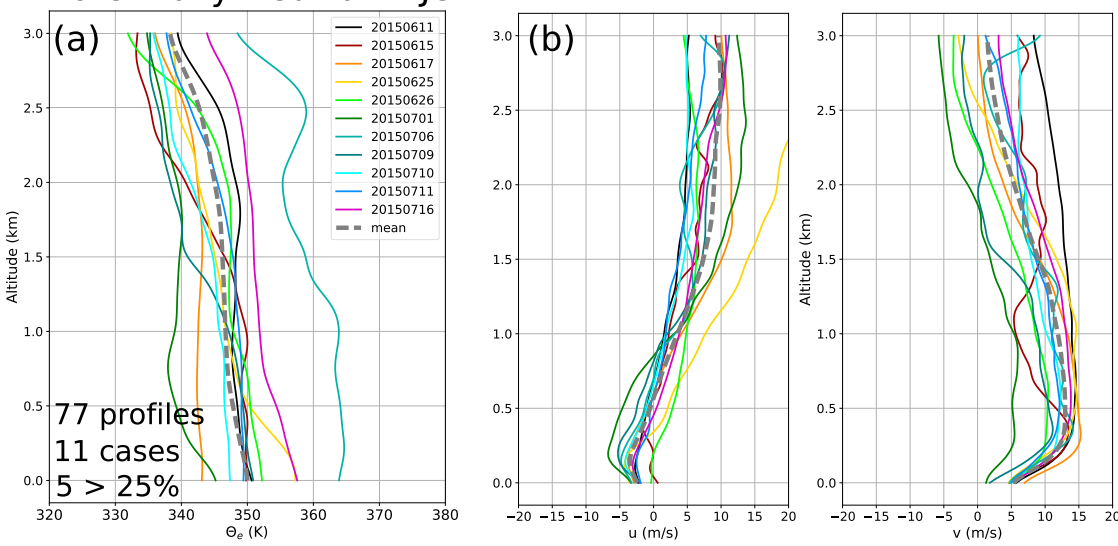

(c)

\section{Potentially Neutral}
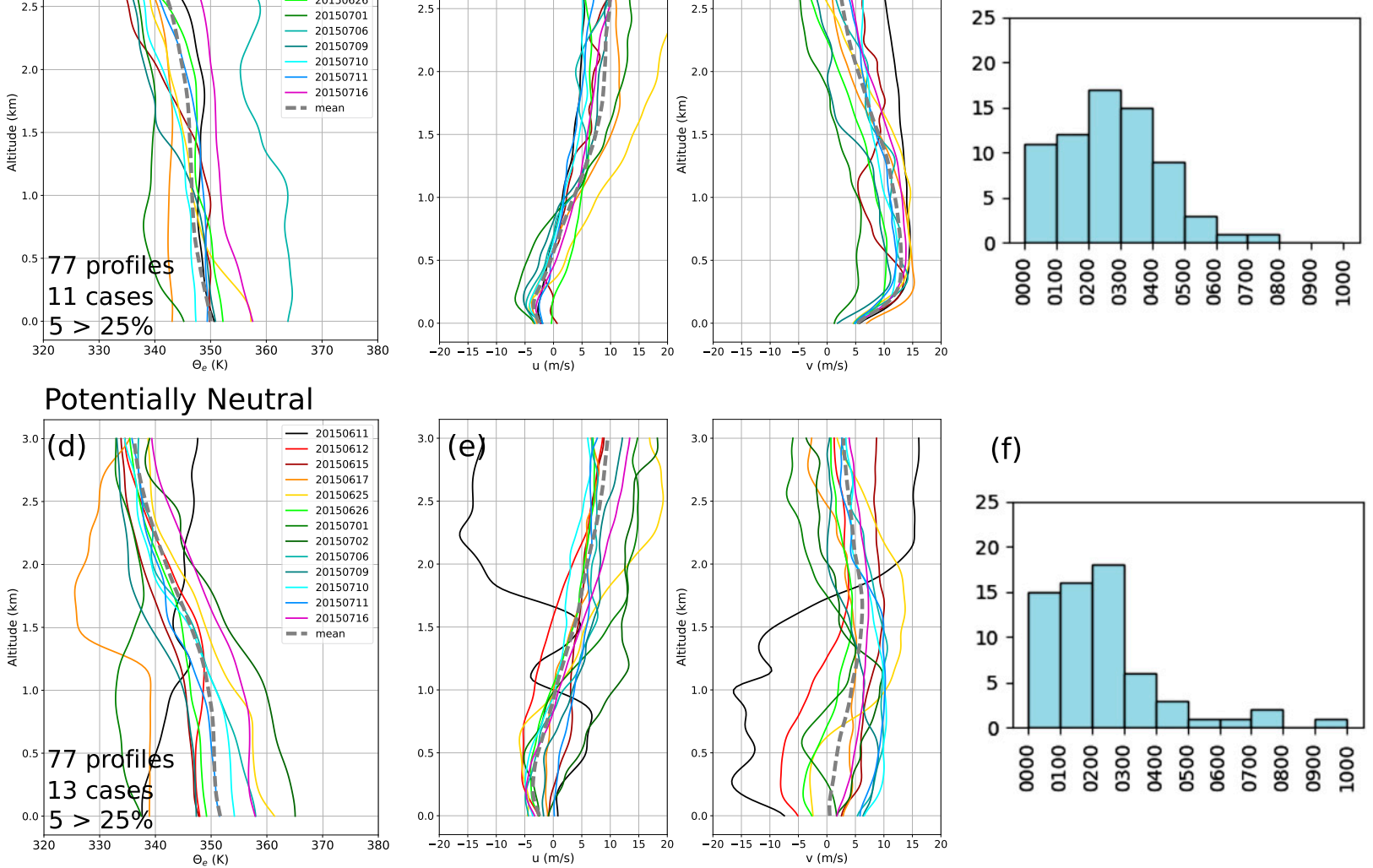

\section{Elevated Instability}
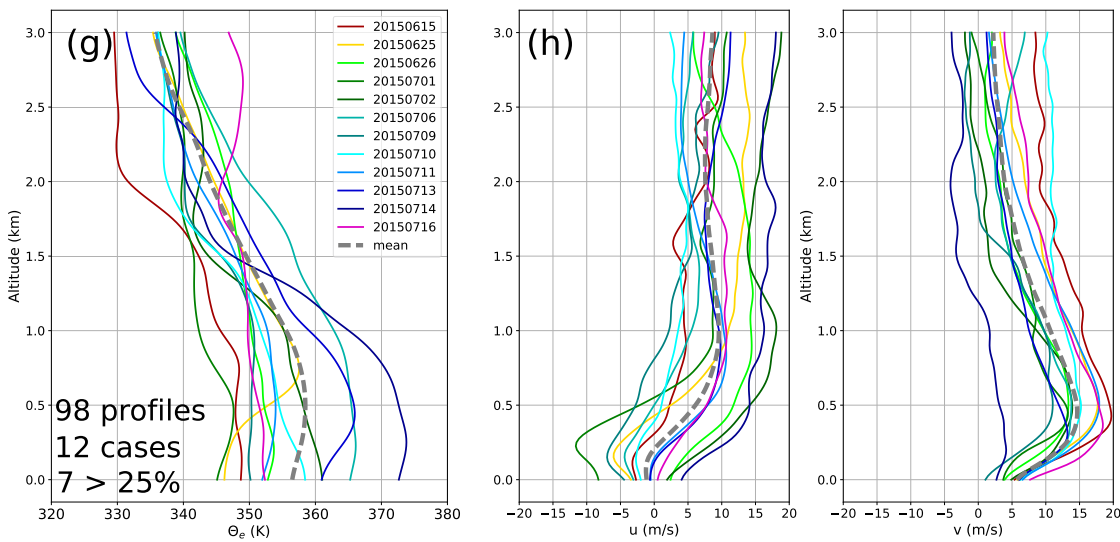

(f)

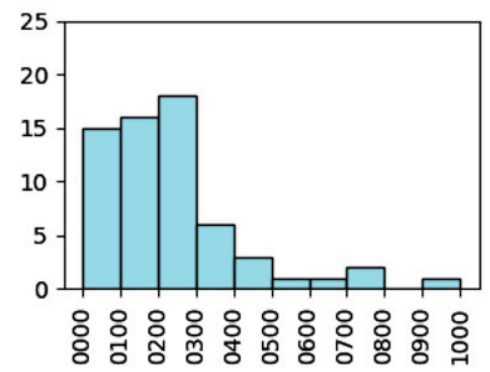

(i)

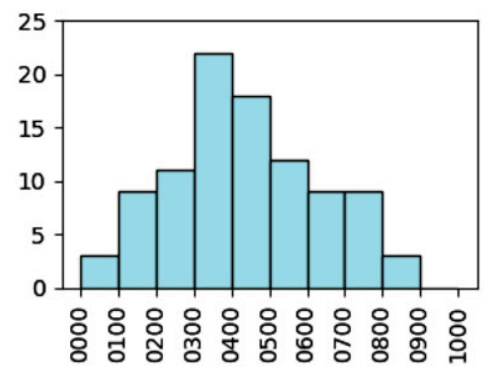

FIG. 3. Mean (solid lines) and standard deviation (semitransparent shading) of (a),(d),(g) $\theta_{e}(\mathrm{~K})$ and (b), (e),(h) $u$ and $v$ (m s ${ }^{-1}$ ) below $3 \mathrm{~km}$ for each case in each cluster. Dates of intensive observing periods (IOPs) are given by different colors. The number in parentheses in the lower left of (a),(d),(g) is the number of cases with more than $25 \%$ of preconvective soundings clustered (listed in Table 3). Cluster means given by the gray dashed line. (c),(f),(i) Histograms showing a distribution of launch times by hour for each cluster.

these parameters in the different environments identified. The elevated instability cluster has a larger distribution of, and on average more MUCAPE and a smaller distribution of, and less MUCIN than the two potentially neutral clusters (Figs. 5a,b). This fits well with the idea that the flux of high $\theta_{e}$ air in an elevated layer contributes to destabilization aloft. The potentially neutral cluster with no jet generally had more MUCAPE and less MUCIN than its counterpart with a jet, which is most likely due to the lack of low-level (potential and static) stability and larger near-surface $\theta_{e}$ values. Distributions of surfaced-based (SB) CAPE and CIN were actually 
Potentially Neutral + Jet

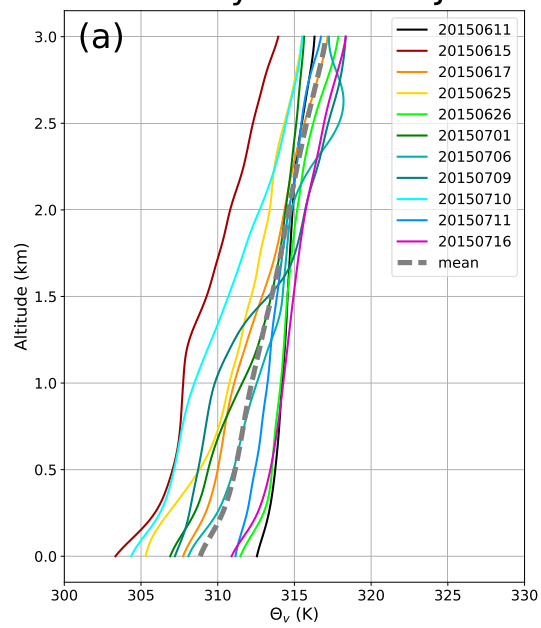

Potentially Neutral

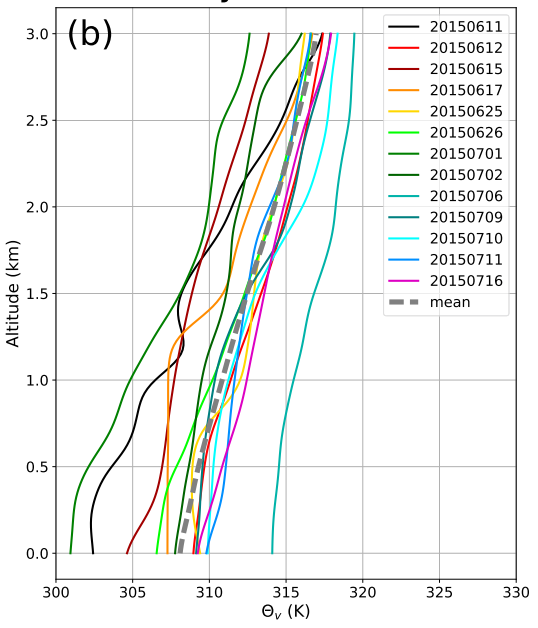

Elevated Instability

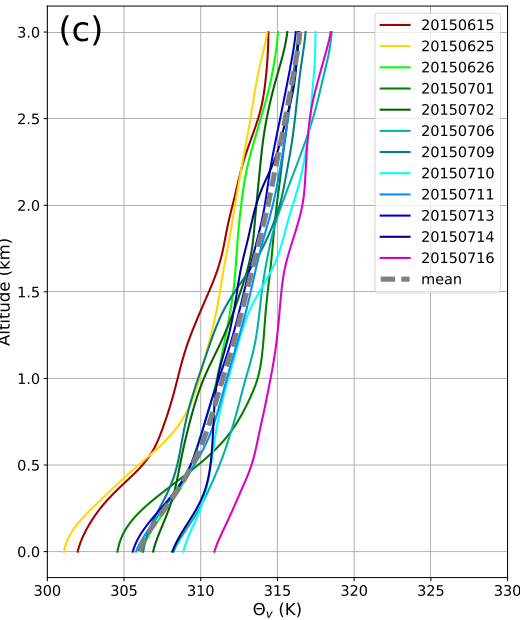

FIG. 4. Mean (solid lines) and standard deviation (semitransparent shading) $\theta_{v}(\mathrm{~K})$ below $3 \mathrm{~km}$ for the (a) potentially neutral + jet, (b) potentially neutral, and (c) elevated instability clusters. Dates of intensive observing periods (IOPs) are given by different colors. Cluster means are given by the gray dashed line.

quite similar between clusters, with slightly larger values of SBCAPE and SBCIN observed in the elevated instability cluster (Figs. 5c,d). In general, MUCAPE is larger than SBCAPE in all three clusters, but MUCIN is also larger. In keeping with the elevated nature of the elevated instability cluster, the majority of the most unstable parcels are located above the surface, though the mean and median are only about $50 \mathrm{hPa}$ above the surface (Fig. 5e). In the other two clusters, the mean difference between the surface pressure and most unstable parcel pressure is very small. In profiles that are nearly potentially neutral, the most-unstable parcel height is sensitive to small changes in $\theta_{e}$ in the profile, which is likely the reason for their large range. Precipitable water had a narrower range and larger mean/ median values in the elevated instability cluster; the high $\theta_{e}$ values are associated with an influx of moisture in the inflow layer. The $0-6-\mathrm{km}$ bulk wind difference (hereafter referred to as shear ${ }^{5}$ ) did not vary much from cluster to cluster, but the $0-1-\mathrm{km}$ bulk wind difference was notably larger in the two clusters with elevated maxima in southerly low-level winds (potentially neutral + jet and elevated instability clusters), and largest in the elevated instability cluster.

\section{b. Composite soundings}

The thermodynamic profiles at low levels of both potentially neutral composites (Fig. 6) resemble the daytime convective boundary layer, but a very shallow inversion

\footnotetext{
${ }^{5}$ Note: Bulk wind difference is often used in lieu of wind shear to demonstrate changes in wind with height.
}

layer is present near the surface of the potentially neutral + jet composite (below about $275 \mathrm{~m}$ ). As discussed in the cluster results, the potentially neutral + jet case has evidence of a low-level wind maximum of 10 $15 \mathrm{~m} \mathrm{~s}^{-1}$ out of the SSE. However, below $800 \mathrm{hPa}$ this cluster was actually drier than both of the other clusters. The greatest $\mathrm{RH}$ is found around $700 \mathrm{hPa}$, around approximately the same level as $\theta_{e}$ profiles in this cluster transition to potentially unstable. In the potentially neutral cluster without strong low-level winds, the dewpoint decreases slowly with height at low levels, and the environment has more moisture over a greater depth than either of the other composites.

At low levels, the elevated instability cluster is nearly isothermal in temperature, and has the largest dewpoint of the clusters. There is an associated increase in lowlevel winds to just over $15 \mathrm{~m} \mathrm{~s}^{-1}$ out of the southwest at about $500 \mathrm{~m}$ above the surface (Fig. 6). The winds are stronger over a deeper layer, and more westerly compared to the wind maximum in the potentially neutral + jet cluster. The major differences in temperature between the clusters are small, and occur almost entirely below $900 \mathrm{hPa}$. Differences in moisture and wind occur over slightly deeper layers, and are larger.

In two of the three clusters, very little stabilization occurred at low levels. When soundings from before 0200, 0300, or 0400 UTC are withheld in the creation of composite soundings (not shown), the primary changes are a very slight deepening of the inversion in the potentially neutral + jet cluster, and a moistening in the potentially neutral cluster, but the same fundamental characteristics remained. Similarly, if composites are computed by first finding the mean of the soundings for 
MUCAPE

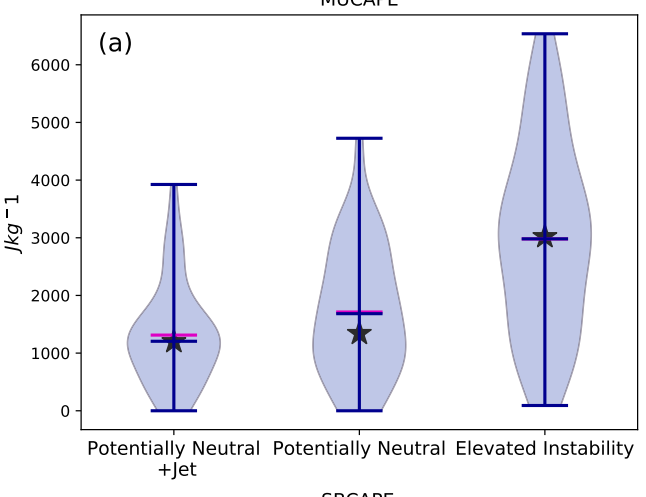

SBCAPE

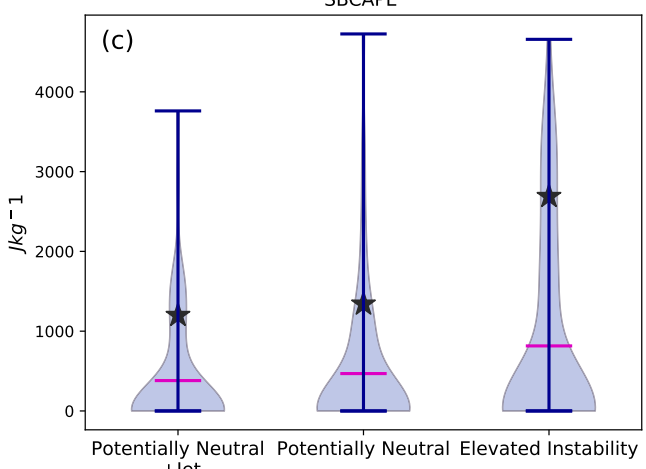

+ et

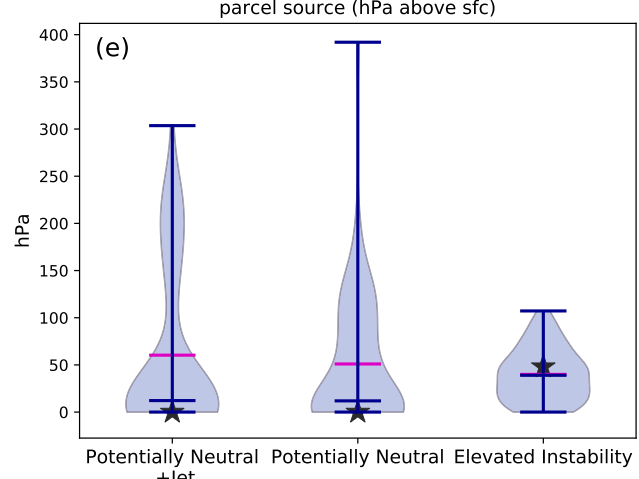

+ jet

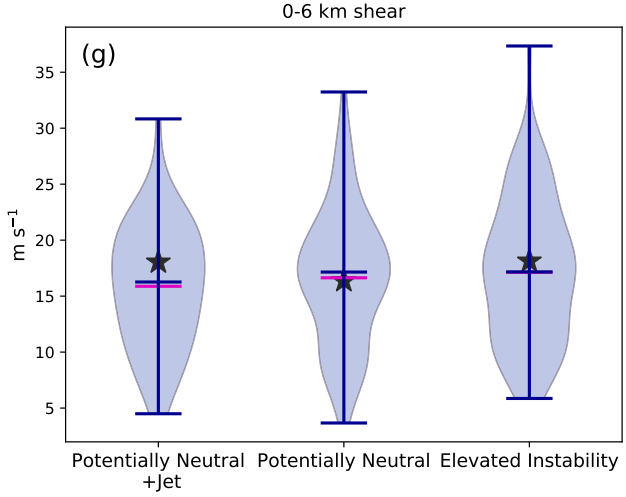

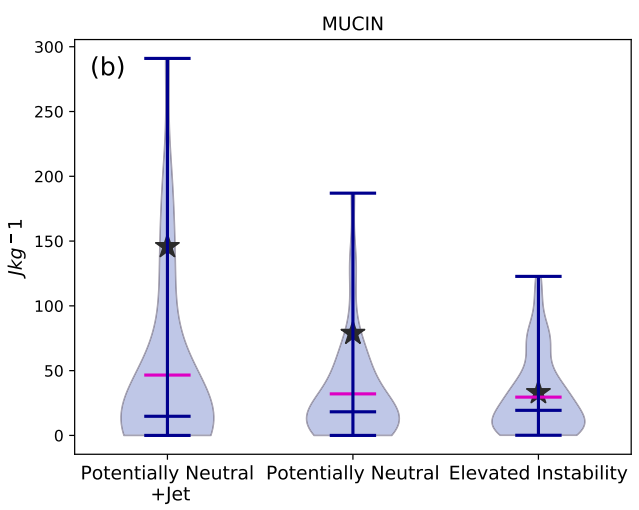

SBCIN

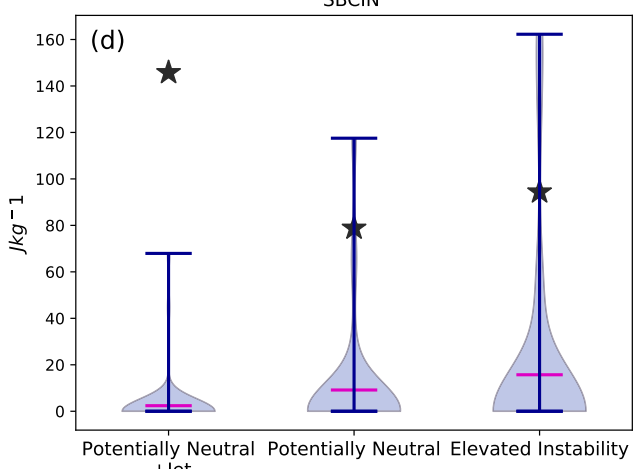

+ Jet

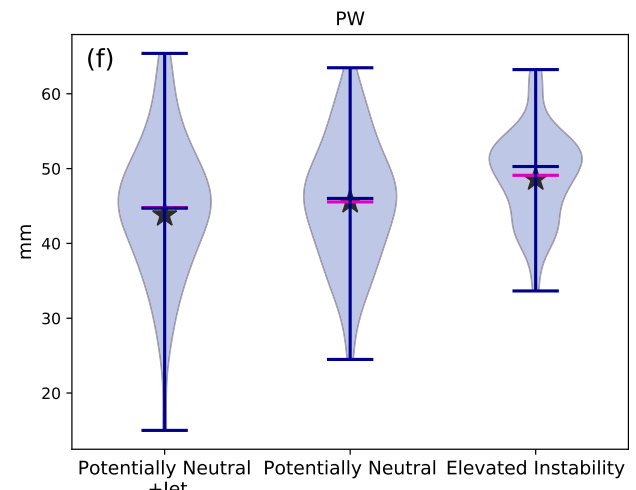

+ Jet

0-1 km shear

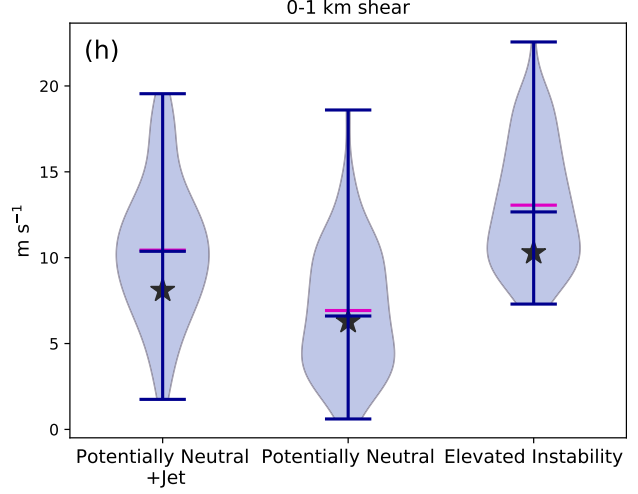

FIG. 5. Violin plots of (a) MUCAPE $\left(\mathrm{J} \mathrm{kg}^{-1}\right)$, (b) MUCIN $\left(\mathrm{J} \mathrm{kg}^{-1}\right)$, (c) SBCAPE $\left(\mathrm{J} \mathrm{kg}^{-1}\right)$, (d) SBCIN $\left(\mathrm{J} \mathrm{kg}^{-1}\right)$, (e) MU parcel source (hPa above surface), (f) precipitable water (PW; mm), (g) 0-6-km shear (knots), and (h) 0-1-km shear (knots) for each cluster. Plots indicate the distribution (shaded), $\mathrm{min} / \mathrm{max}$ (blue horizontal lines at top and bottom of plot respectively), median (middle blue horizontal line), and mean (magenta) of the set of soundings. The mean and median are equal if the magenta line is not visible. The green star is the variable value in the composite soundings. 


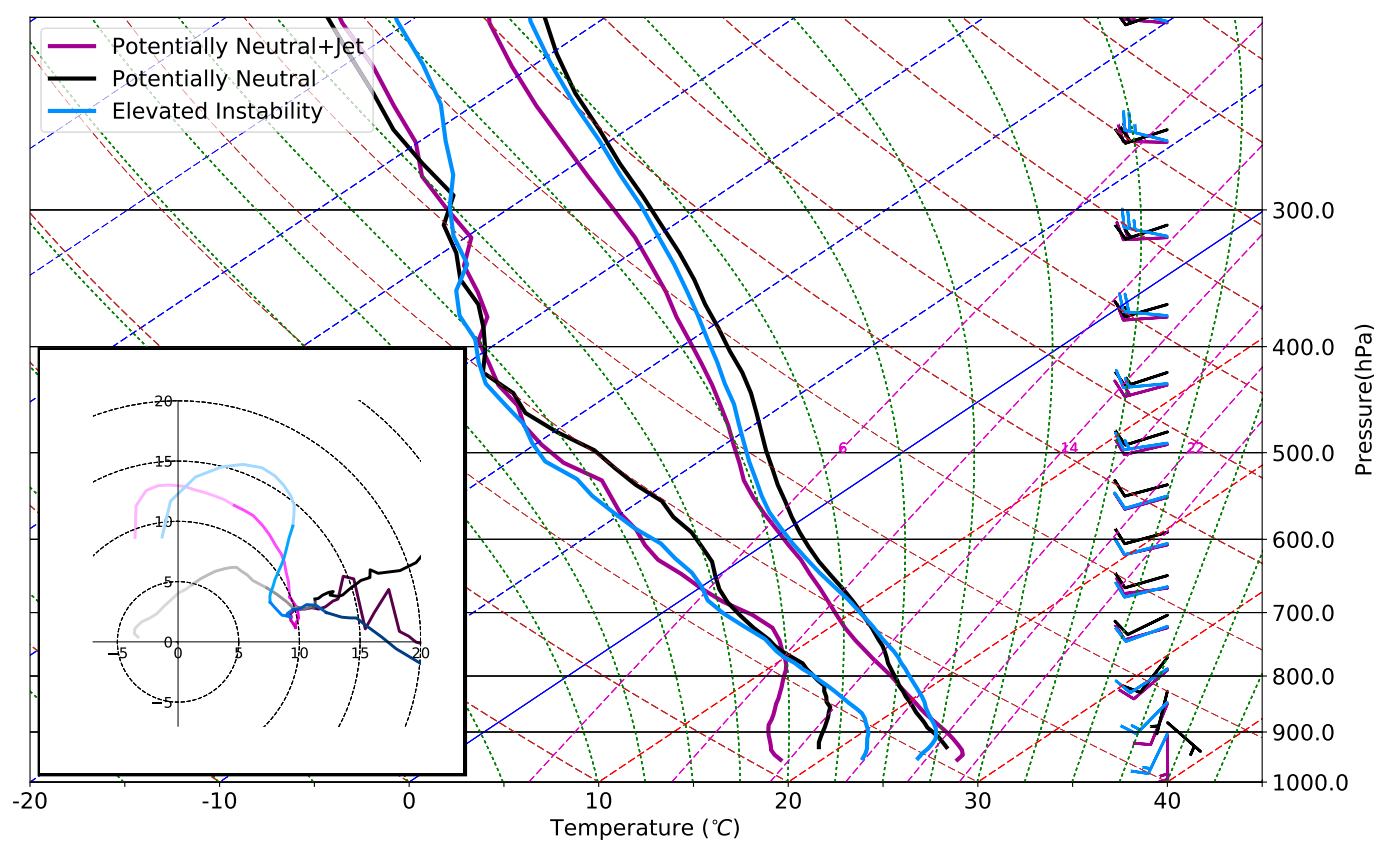

FIG. 6. Skew $T-\log p$ plots and hodographs (inset) of composites of the three clusters. Winds in $\mathrm{m} \mathrm{s}^{-1}$ (half barb $=$ $5 \mathrm{~m} \mathrm{~s}^{-1}$ ). Shading in the hodograph changes at $1-\mathrm{km}$ intervals from light to dark.

each case in a cluster and then compositing on the case means, the fundamental results remain the same (not shown). While it is possible that the method presented in this work is slightly biased by cases where a large number of soundings were launched, computing the case mean first unfairly gives the same weight to a case where, for example, 1 of 10 soundings was placed in the same cluster as another case where 10 of 10 soundings were placed in the same cluster. The most notable difference between the method shown and the case mean method is that the potentially neutral cluster is cooler and drier at mid- and low levels than in the composite presented in Fig. 6. So although there are limitations to both choices, multiple methods give similar results.

Convective parameters for the three clusters are plotted in Fig. 5. As desired, the compositing method conserves MUCAPE well, but the composite MUCIN, SBCAPE, and SBCIN all tend on the larger (in magnitude) tail of the highly skewed distributions. Precipitable water, 0-6-km shear, and $0-1-\mathrm{km}$ shear are also relatively well conserved. Parcel source was near the median in all three clusters, and essentially at the surface in the two potentially neutral clusters.

\section{c. Composite environments}

0000 UTC RAP analyses from cases associated with clustered soundings were used to create composite environments for each cluster. The composite environment of any particular cluster shown in Fig. 7 only includes cases where more than $25 \%$ of the preconvective soundings were grouped in that cluster. For example, the Elevated Instability composite environment is made up of 0000 UTC RAP analyses from cases where $25 \%$ or more of the preconvective soundings were clustered with in the Elevated Instability category. Cases that meet this requirement for a given cluster are identified in Table 3 by an asterisk next to the number of preconvective soundings from that case in that cluster. For a more visual representation, the cases used in a particular composite based on the above requirement are also denoted in Figs. 1 and 2 by completely filled colored dots that represent the different clusters. ${ }^{6}$ The above method of identifying cases to include in composites was selected in order to reduce the influence of cases where one or two profiles from a day with many preconvective soundings were clustered differently from the bulk of the profiles on that day. Qualitative observations of these outliers suggest that they are just that. Despite this, in a qualitative comparison between the more representative composites described above and composites that included all cases represented by any number of profiles in a given cluster, the differences were small. The centroid for each case used

\footnotetext{
${ }^{6}$ Half-filled dots indicate that some soundings from a given case were in a given cluster, but that the number clustered was less than $25 \%$ of the total preconvective soundings.
} 
Potentially Neutral + Jet
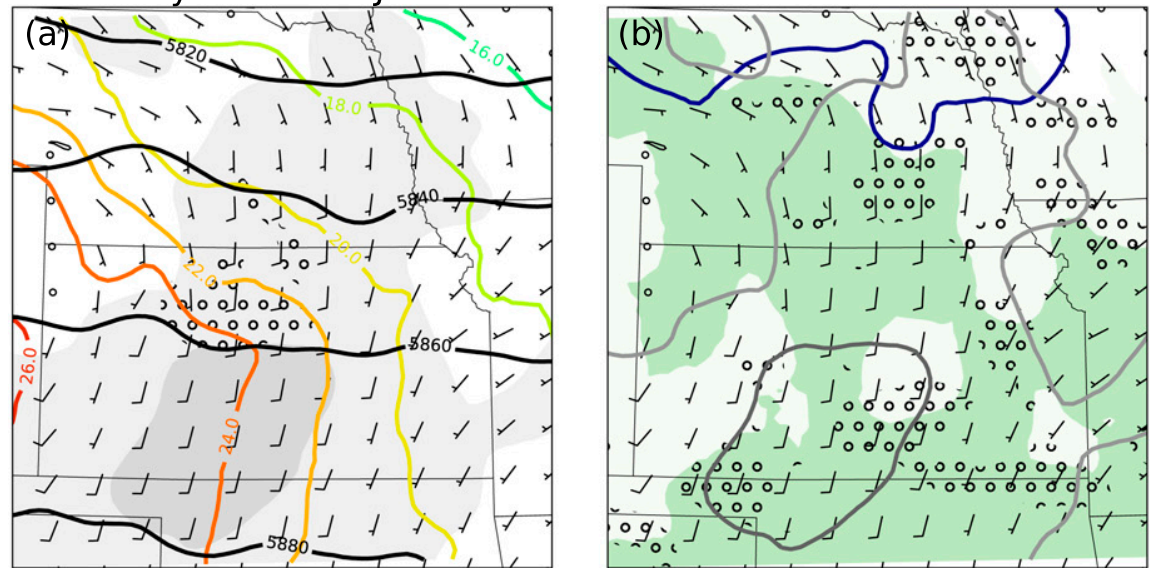

Potentially Neutral
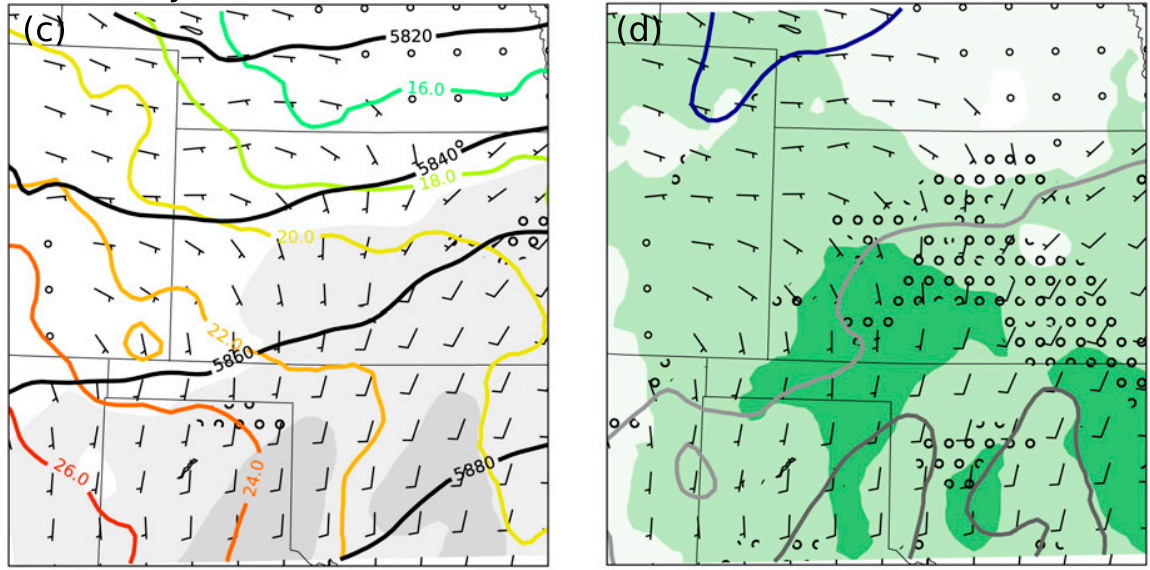

\section{Elevated Instability}
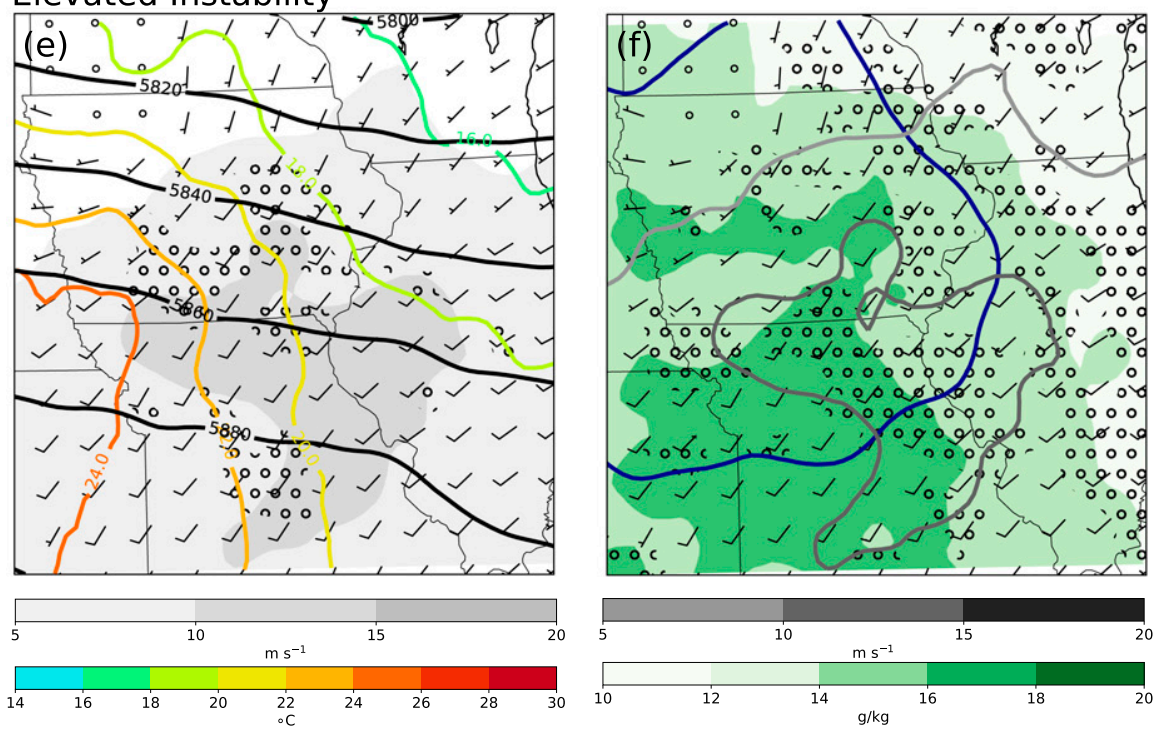

FIG. 7. Composite plots depicting 0000 UTC RAP analysis of the (a),(b) potentially neutral + jet, (c),(d) potentially neutral, and (e),(f) elevated instability clusters. (a),(c),(e) 500-hPa heights $\left(\mathrm{m}\right.$; black), 850-hPa wind speed (grayscale) and barbs (half barb $=5 \mathrm{~m} \mathrm{~s}^{-1}$ ), 850-hPa temperature $\left({ }^{\circ} \mathrm{C}\right.$; color contours), and 850-hPa temperature advection $>\sim 0.5 \mathrm{~K} \mathrm{~h}^{-1}$ (stippled with open circles). (b),(d),(f) $250 \mathrm{hPa}$ winds $>50 \mathrm{kt}\left(1 \mathrm{kt} \approx 0.5144 \mathrm{~m} \mathrm{~s}^{-1}\right.$ ) (unfilled dark blue contour), 850-hPa wind speed (unfilled gray contours), 850-hPa wind barbs $\left(\mathrm{m} \mathrm{s}^{-1}\right), 850-\mathrm{hPa}$ water vapor mixing ratio $\left(\mathrm{g} \mathrm{kg}^{-1}\right.$; green filled contours), and $850-\mathrm{hPa}$ moisture advection $>0.2 \mathrm{~g} \mathrm{~kg}^{-1} \mathrm{~h}^{-1}$ (stippled with open circles). 
to generate the composite was selected by computing the centroid of the soundings for that case in a given cluster.

In all three clusters, upper-level flow is generally zonal with a slight southerly (potentially neutral, no jet) or northerly (elevated instability) component and the warmest air at $850 \mathrm{hPa}$ is located in the west-southwest (Figs. 7a,c,e). Upper-level winds of greater than $25 \mathrm{~m} \mathrm{~s}^{-1}$ cover a broad area in the elevated instability composite, but are strongest only in the far north of the potentially neutral composites (Figs. 7b,d,f). A low-level wind maximum is present in all three clusters, but extends farther north in the potentially neutral + jet and elevated instability composites. Stronger $850-\mathrm{hPa}$ winds cover a broader region in the elevated instability cluster, and southerly winds extend throughout nearly the entire region, where they begin to shift parallel to the isotherms in the northern portions of the potentially neutral composites. Consequently there are more regions of warm air advection associated with the interaction of the 850-hPa wind maximum and southwest-northeast temperature gradient (Figs. 7a,c,e). Additionally, there is more 850-hPa moisture in the elevated instability cluster (Figs. 7b,d,f) than either of the other clusters. This leads to greater spatial coverage of moisture advection by the low-level wind maximum consistent with the observed increases in $\theta_{e}$ during elevated instability cases. In the potentially neutral cluster with a low-level wind maximum, the weak moisture gradient (or decreasing moisture to the south in places), leads to more sporadic moisture advection, and a composite that is generally consistent with observations of little change in $\theta_{e}$ ahead of convection during potentially neutral cases (Fig. 7b). The potentially neutral cluster has more moisture and a more coherent region of moisture advection than the potentially neutral + jet cluster, consistent with the higher composite dewpoints in Figs. 6 and 7d. All three clusters have clear evidence of convergence of similar magnitudes at the left terminus of the lowlevel wind maximum (not shown), but the strongest signal of advection of warm, moist air is in the elevated instability case.

Broadly speaking, the MCSs observed on days with environments that best fit in the elevated instability category were organized into a single dominant structure (Figs. 1e,h,i,j,1,m). Nearly all cases had bowing (Figs. $2 \mathrm{~m}, \mathrm{i}),{ }^{7}$ back-building (Fig. 2h), or regions of both (Figs. 2e,j,1), and had less discrete cells than their potentially neutral counterparts (both with and without

\footnotetext{
${ }^{7}$ Bowing in this case occurred about an hour before it reached the PECAN array.
}

the LLJ) a similar amount of time after initiation. ${ }^{8}$ Nearly all of the cases with predominantly potentially neutral environments had multiple or unclear boundaries with several linear elements and a number of discrete cells (Figs. 2b,c,f,k,o). These no-jet cases also tended to have a number of soundings that were difficult to categorize as pre- or postconvective. In several cases, winds were northerly or calm, and observations were primarily taken between multiple regions of convection, but little-to-no stabilization had occurred at low levels (from any source). For example, the 12 June and 15 June cases, an initial, convective line formed along a boundary ahead of the mobile asset locations (Figs. 2b,c). In both cases, this convection moved east and dissipated as new, stronger, convection developed to the west of the target locations and was intercepted by mobile teams. The MCSs that developed in predominately potentially neutral + jet environments can generally be described as quasilinear. These MCSs tended to have a more defined leading convective line (as opposed to multiple boundaries) and a large statiform region. Several cases also had a number of embedded discrete cells (Figs. 2a,d,g,k,o). In the future, a more detailed analysis of these relationships between the clusters and resulting convection could prove enlightening. In all three clusters, the conditions were often cloudy at some level over an extended period before the passage of convection. Some cases in the elevated instability cluster did appear to have longer periods of clear conditions, and more high clouds. However, a deeper exploration of the relationship between high/ low clouds and stabilization would be worthwhile, but it is beyond the scope of this paper.

\section{d. Environment evolution in select cases}

Composite analysis on cluster environments provides some general insight into different types of preconvective environments observed during PECAN. However, it cannot capture the spatial and temporal variability that exists from case to case or even within a single case. To this end, the evolutions of environments from three cases, one from each of the major clusters, are examined in closer detail. The cases chosen each represent a large proportion of the soundings clustered in their respective categories and are as follows: 1) potentially neutral + jet: 17 June $2015,2)$ potentially neutral: 12 June 2015 , and 3) elevated instability: 13 July 2015.

\footnotetext{
${ }^{8}$ An exception to this is the 14 July case, when an MCS did not form until well after the end of the IOP (Fig. 2n).
} 
To visualize the temporal variability, soundings launched from MG locations were interpolated to a 100-m vertical grid and thermodynamic and kinematic fields were plotted as a function of height and launch time. Gaps in the analysis indicate missing data, where soundings did not reach $5 \mathrm{~km}$ (this was rather common for launches into convection). Ascent over the first $5 \mathrm{~km}$ usually occurs over the first $\sim 20 \mathrm{~min}$ of a launch, and adjustments for launch duration would likely not impact conclusions from this analysis. This method also assumes MGs were collocated throughout the duration of the IOP, and while they were not always exactly collocated on 17 June or 12 June cases, they were close enough to have sampled a similar evolution of the preconvective environment.

On 17 June and 13 July, the gust front passages occurred around 0500 UTC and just before 0630 UTC respectively, and are clearly visible in a southerly to northerly wind shift and a near-surface decrease in both $\theta_{e}$ and $\theta_{v}$ fields (Figs. 8a,b,e,f). General postconvective environments will be discussed in greater detail in section 5 , but it is interesting to note that while the initial gust front and northerly wind shift was observed around 0500 UTC on 17 June, deeper northerly winds and a more prominent decrease in $\theta_{v}$ occurred about 30 min later (Figs. 8a,b). In both cases, an increase in lowlevel winds was observed between 0200 and 0300 UTC, over an elevated layer below 1 km (Figs. 8a,e). On 13 July, much like the common conceptual model, $\theta_{e}$ increased over the same layer throughout the observing period (Fig. 8e). However, on 17 June, the $\sim 3-\mathrm{km}$-deep layer of nearly constant $\theta_{e}$ remained essentially unchanged until the passage of the gust front, despite the development of a low-level wind maximum where southerly wind speeds actually exceeded those observed on 13 July (Fig. 8a). In both cases, low-level zonal winds were weak, but a slightly larger easterly component was observed in the lowest $1 \mathrm{~km}$ on 17 June (Figs. 8b,f).

Of the other elevated instability cases, the 25 June case (Fig. 2e; Described in greater detail in Peters et al. 2017) evolves most similarly to 13 July, destabilizing rapidly in an elevated layer. Other cases in this cluster do have an increase in $\theta_{e}$ just above the surface, but evolve more slowly with time, and at times have a 1-2-km-deep layer of nearly constant $\theta_{e}$ resembling that of the other two clusters. Other potentially neutral + jet cases are generally quite similar to that of $17 \mathrm{June}$, and cases that are split between the two potentially neutral cases tend to resemble the potentially neutral cluster early, and transition to the potentially neutral + jet with the onset of the LLJ.

While the 12 June case has a 2-km-deep layer of nearly constant $\theta_{e}$, it is distinctly different from 17 June because it lacks low-level southerly winds. On this day, mobile assets were located on the cool side of a shallow surface front in a region of northerly low-level winds (northerly winds below $1 \mathrm{~km}$ visible in Fig. 8c). Surface observations indicate that a southerly to northerly wind shift was accompanied by temperature changes of only $1^{\circ}-2^{\circ} \mathrm{C}$ across the boundary, and soundings on the cool side of the boundary indicate that cooling was over a very shallow layer. Although an initial line of convection initiated to the south and east of the mobile assets along this boundary, it moved southeast, and sounding observations did not appear to be influenced by convectively generated outflow until between 0330 and 0430 UTC when new convection initiated along the stronger thermal gradient associated with the front, and essentially on top of mobile assets. Even then, it is difficult to distinguish between convective outflow and changes associated with the front during this period. Around 0600 UTC, much more vigorous convection passed over the MGs, and is associated with a decrease in $\theta_{v}$ over a deeper layer and a shift to westerly winds over the same layer. Surface and sounding observations suggest a similar story unfolded on the 15 June and on 26 June. Soundings from other cases in this cluster appear to be more on the early side (before 0200 UTC).

In summary, in environments that resemble the elevated instability conceptual model, $\theta_{e}$ evolves with time-sometimes quite rapidly. In environments with 2-3-km-deep potentially neutral layers, $\theta_{e}$ evolves slowly (if at all), even when a strong low-level wind maximum develops. Furthermore, $\theta_{e}$ on the cool side of a frontal boundary may not change much with time in the absence of convection, and may have little-to-no increase with height, even when there is some evidence of a lowlevel wind maximum above the frontal boundary.

\section{Postconvection}

Changes in virtual potential temperature $\left(\theta_{v}\right)$ from pre- to postconvective environments $\theta_{v}^{\prime}$ were computed to explore characteristics of postconvective environments observed during PECAN MCSs. A preconvective sounding representative of the environment just before the passage of the MCS-produced density current was subjectively identified using $\theta_{e}, \theta_{v}$, and wind profiles from all platforms as well as radar fine lines where appropriate. Soundings were interpolated to common vertical levels, and the mean $\theta_{v}$ perturbation of the observed postconvective environment was computed for each case (Fig. 9). For this analysis, soundings that were ahead of the precipitation, but after the passage of a gust front were included to capture the full range of outflow characteristics. However, for this study, wavelike features were not considered in distinguishing outflow boundaries, in part due to the complexity of 

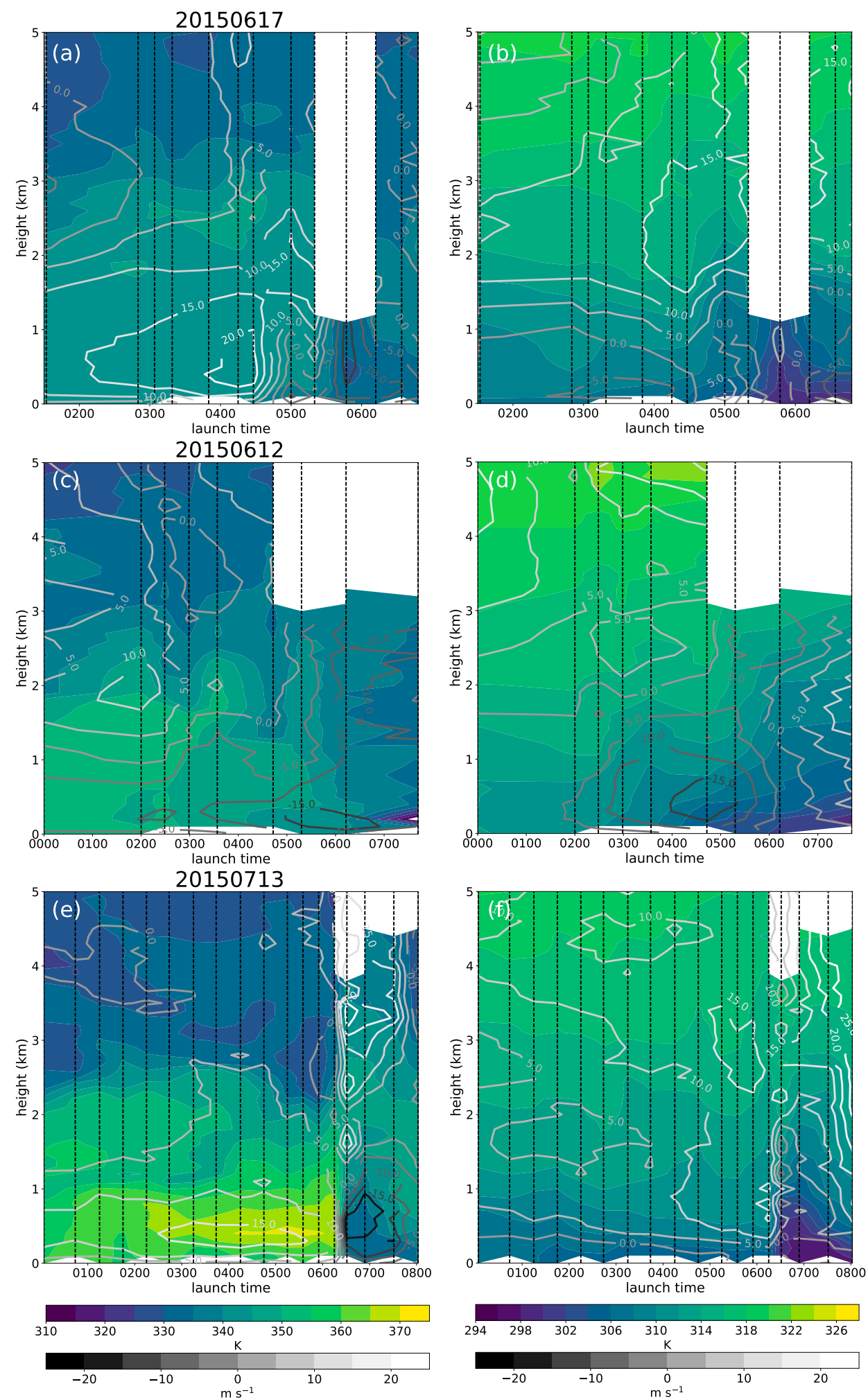

FIG. 8. Time-height diagrams of MG launches on (a),(b) 17 Jun, (c),(d) 12 Jun, and (e),(f) 13 Jul. (a),(c),(e) $\theta_{e}$ (filled contours; K) and meridional wind (unfilled contours; $\mathrm{m} \mathrm{s}^{-1}$ ). (b),(d),(f) $\theta_{v}$ (filled contours; K) and zonal wind (unfilled contours; $\mathrm{m} \mathrm{s}^{-1}$ ). 


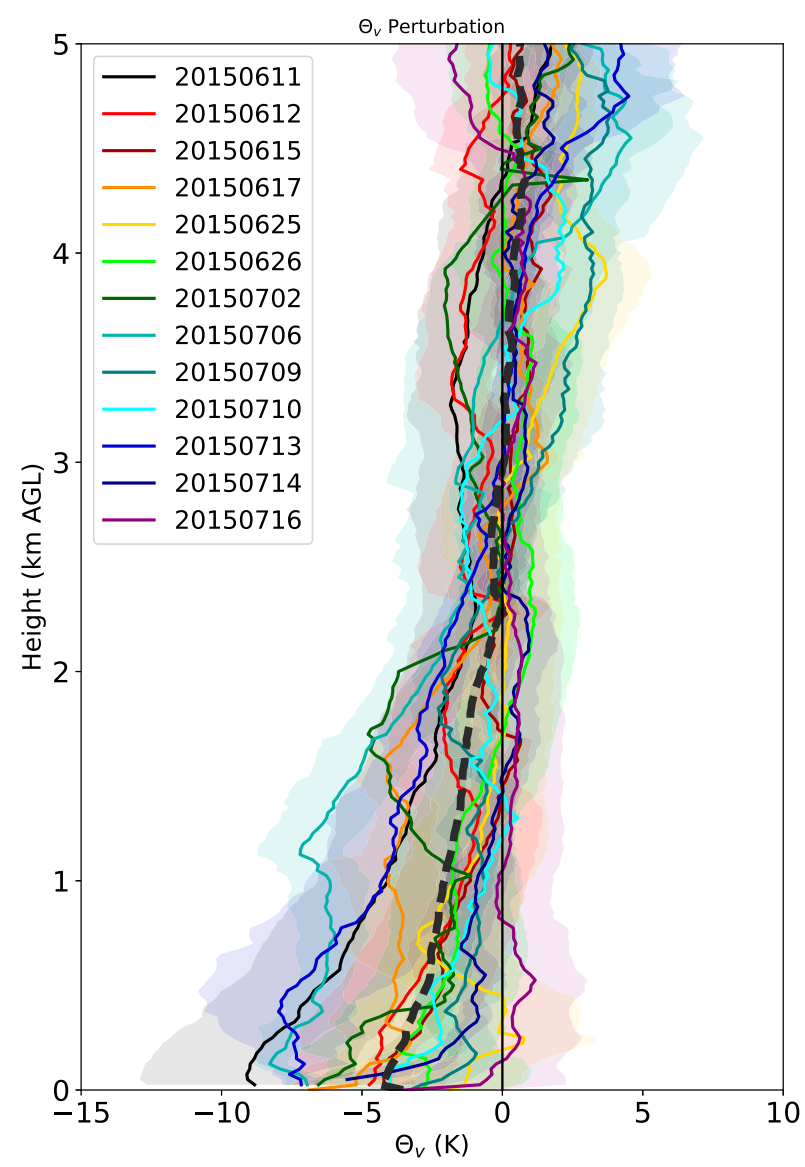

FIG. 9. Average $\theta_{v}$ deficit $(\mathrm{K})$ of postconvective soundings. Shading indicates $\pm 1 \sigma$. The composite $\theta_{v}$ deficit $(\mathrm{K})$ for all cases is shown by the gray dashed line.

identifying them in several cases. 149 soundings were identified as postconvective and used in this analysis. A summary of the statistics for the postconvective soundings is shown in Table 4.

Despite the nocturnal nature of the MCSs observed, a cold pool was observed in nearly every case. ${ }^{9}$ It is clear from Fig. 9 that there is substantial variability in the depth and strength of the change in $\theta_{v}$ from case to case, and even within a single case. Some cases, like 17 June have the greatest decrease in $\theta_{v}$ at the surface, while several other cases, like 25 June have the greatest decrease in $\theta_{v}$ above the surface. Still other cases, like 16 July, have almost no change in $\theta_{v}$ with the passage of convection except in the lowest $150 \mathrm{~m}$. Table 4 highlights several extremes in observed changes in $\theta_{v}$ seen in Fig. 9. The largest mean decrease in $\theta_{v}$ was $-9.10 \mathrm{~K}$, observed during

\footnotetext{
${ }^{9}$ On 11 July, several soundings were launched before and after the passage of a bore, but none of them observed a density current which was likely present closer-to or behind the convective region.
}

TABLE 4. A simple summary of changes in virtual potential temperature $\theta_{v}$. Computed quantities highlight notable features from the case mean vertical profiles of $\theta_{v}^{\prime}$ shown in Fig. 9. $\theta_{\mathrm{vmax}}^{\prime}$ is the magnitude of the largest observed average decrease in $\theta_{v} . \theta_{\mathrm{vmax}}^{\prime}$ hgt is the height at which $\theta_{\mathrm{vmax}}^{\prime}$ occurred. $\theta_{v}^{\prime}$ top is the minimum height in which the mean difference between $\theta_{v}$ in pre- and postconvective soundings is no longer negative. If a second layer of $-\theta_{v}$ of equal or larger magnitude exists above a shallow layer of weakly $-\theta_{v}$, the parenthetical number is the top of that second layer. Bold numbers highlight largest, deepest, or most elevated observed $\theta_{v}$ deficits. Italicized numbers highlight smallest or shallowest $\theta_{v}$ deficits.

\begin{tabular}{lcccl}
\hline \hline Date & $\theta_{v}^{\prime}$ sfc $(\mathrm{K})$ & $\theta_{\text {vmax }}^{\prime}(\mathrm{K})$ & $\theta_{\text {vmax }}^{\prime}$ hgt $(\mathrm{m})$ & $\theta_{v}^{\prime}$ top $(\mathrm{km})$ \\
\hline 11 Jun & $\mathbf{- 8 . 8 2}$ & $\mathbf{- 9 . 1 0}$ & 50 & $\mathbf{4 . 3 5 0}$ \\
12 Jun & -4.74 & -4.74 & 0 & 2.275 \\
15 Jun & -4.18 & -4.22 & 25 & 1.400 \\
17 Jun & -6.88 & -6.88 & 0 & 2.800 \\
25 Jun & -1.90 & -3.02 & $\mathbf{7 0 0}$ & $0.200(1.700)$ \\
26 Jun & -2.85 & -3.77 & 200 & 1.725 \\
2 Jul & -6.55 & -6.55 & 0 & 2.400 \\
6 Jul & -6.95 & -8.29 & 100 & 3.675 \\
9 Jul & -3.28 & -3.28 & 0 & 2.500 \\
10 Jul & -3.99 & -4.01 & 50 & 1.200 \\
13 Jul & -7.16 & -7.98 & 350 & 3.000 \\
14 Jul & -5.53 & -5.53 & 0 & 1.375 \\
16 Jul & -3.49 & -3.49 & 0 & 0.150 \\
\hline
\end{tabular}

the 11 June case, just above the surface. The 25 June, case observed only a $-1.90 \mathrm{~K} \theta_{v}^{\prime}$ at the surface over a very shallow layer. However, a mean $\theta_{v}^{\prime}$ of $-3.02 \mathrm{~K}$ was observed at $700 \mathrm{~m}$ above the surface above a layer with little change (and even a slight increase) in $\theta_{v}$.

Six out of the 13 cases included in this analysis observed the largest decrease in $\theta_{v}$ at the surface. Another three cases observed the largest decrease in $\theta_{v}$ just above the surface, and four cases observed the largest decrease in $\theta_{v}$ well above the surface. In these cases, the height of largest decrease in $\theta_{v}$ ranged from 100 to $700 \mathrm{~m}$ above the surface. The average depth of the observed $-\theta_{v}^{\prime}$ (a measure of cold pool depth) ranged from $150 \mathrm{~m}$ to $4.350 \mathrm{~km}$ between cases. The two deepest observed cold pools, on 11 June and 6 July, also had the greatest maximum change in $\theta_{v}$ and two of the top three largest observed decreases in surface $\theta_{v}$. The shallowest layer of mean near-surface $-\theta_{v}^{\prime}$ was observed on 16 July and not in conjunction with the smallest decrease in $\theta_{v}$. Rather, the smallest decrease in surface $\theta_{v}$ observed occurred on 25 June, a day when the largest decrease in $\theta_{v}$ occurred aloft. The average of the mean observed depth of $-\theta_{v}^{\prime}$ for the 13 PECAN cases with postgust front observations is $2.08 \mathrm{~km}$. The average observed change in $\theta_{v}$ is $-5.1 \mathrm{~K}$ at the surface and the average maximum change in $\theta_{v}$ is $-5.45 \mathrm{~K}$.

In the literature it has been noted that in cases with strong low-level stable layers, convective downdrafts may 
not be strong enough to penetrate to the surface, and instead can produce gravity waves or bores (e.g., Trier and Parsons 1993; Carbone et al. 1990; Parker 2008). In these cases, convectively cooled outflow may mix out before it reaches the surface, or more likely, spread out in a layer above the surface when they reach their level of neutral buoyancy. This acts to cool the upper regions of the inversion layer. In some cases, a particularly strong downdraft may actually still reach the surface, even when a relatively strong stable layer is present. When this happens, the greatest cooling may still be seen aloft, where the layer of warm air at the top of the inversion is cooled more than the relatively cooler layer near the surface. One might expect then to find a relationship between the observed outflowproduced cooling profile and characteristics of the stable layer. A comparison of the height of the greatest decrease in $\theta_{v}$ to the strength and depth of the observed preconvective stable layer ${ }^{10}$ shows evidence of this (Fig. 10).

A linear regression between the depth of the greatest $\theta_{v}^{\prime}$ and the stable layer properties of strength and depth indicates, at least to a first order approximation, that there is a relationship between them (Fig. 10). Stable layer strength (Fig. 10a) appears to have a stronger relationship to the depth of observed $\theta_{v}^{\prime}$ than stable layer depth (Fig. 10b) with $R^{2}$ values of 0.780 and 0.545 respectively. Even though it is often thought that convectively cooled outflow may not reach the surface in the presence of a strong stable layer (e.g., Trier and Parsons 1993; Marsham et al. 2010), it is not unusual to find a cold pool at the surface during an MCS in a stable low-level environment. That said, there is evidence that properties of the stable layer do modify the cold pool structure. Another possible explanation of this elevated maximum in cooling is that rather than a true cold pool, this is a "Type C" bore as described in Rottman and Simpson (1989), where the density current and bore move at the same speed, and a semipermanent deepening of the inversion layer leads to a decrease in $\theta_{v}$ in an elevated layer. More data are needed in environments with strong and deep stable layers, and additional work is needed to explore these relationships further.

Other relationships between pre- and postconvective environments were explored, including: freezing layer depth and cold pool depth, stable layer strength/depth and cold pool depth, and stable layer strength/depth and

\footnotetext{
${ }^{10}$ The depth of the stable layer was taken as the height at which the lapse rate becomes greater than the moist adiabatic lapse rate. Stable layers that did not begin at the surface were not included. If shallow regions $(<100 \mathrm{~m})$ of conditional instability existed between two stable layers, the top of the uppermost stable layer was taken to be the depth. The stable layer strength is defined as the difference between $\theta_{v}$ at the top of the inversion and the surface.
}

cold pool intensity at the surface. No clear trends were seen in those relationships.

Given the results of the cluster analysis presented in earlier sections of the paper, it initially came as somewhat of a surprise that the majority of preconvective soundings in every observed PECAN case did have a low-level stable layer (shown by the shaded fraction of the marker in Fig. 10). However, it is not unusual for low-level absolute stability and potential instability or neutrality to exist in the same layer. As noted by the bars marking one standard deviation, there is a large amount of variability in the strength, and especially the depth, of the average preconvective stable layer (Fig. 10). A large number of variables can influence the stability at low levels including moisture (in the air, vegetation, and soil), cloud cover, other convection, location relative to frontal boundary, and slope and strength of frontal boundary. A combination of these and other factors likely influenced environments observed during PECAN on any given night. This in-turn influences the relationship between observed MCSs and their environment.

\section{Discussion and summary}

Analysis of nearly 300 soundings launched in preconvective MCS environments during PECAN resulted in identification of three distinct categories, 1) potentially neutral, 2) potentially neutral + jet, and 3) elevated instability, of environments observed before the passage of the convective line. One category, "elevated instability," fits the Trier and Parsons (1993) conceptual model of nocturnal convection well. A near-surface inversion is topped by a layer of high $\theta_{e}$ air and potential instability that appears to increase in magnitude and deepen with time. A corresponding increase in low-level southerly winds was also seen, indicating the presence of a low-level jet. In this category, low-level winds generally maximized at a higher altitude, greater magnitude, and with a greater westerly component than in the potentially neutral category. However, the layer of southerly wind increases was below the layer of maximum $\theta_{e}$ in both cases.

The second category, termed "potentially neutral + jet," had only a weak near-surface stable layer, and near-constant $\theta_{e}$ in the lowest $2.5 \mathrm{~km}$. Profiles in this category did tend to be from slightly earlier in the IOP than the elevated instability category. However, the majority of profiles in this category still came from soundings launched after sunset ( $\sim 0200$ UTC). Lowlevel wind maxima in the potentially neutral category tended to occur closer to the surface, and had a stronger near-surface easterly component. Despite the 

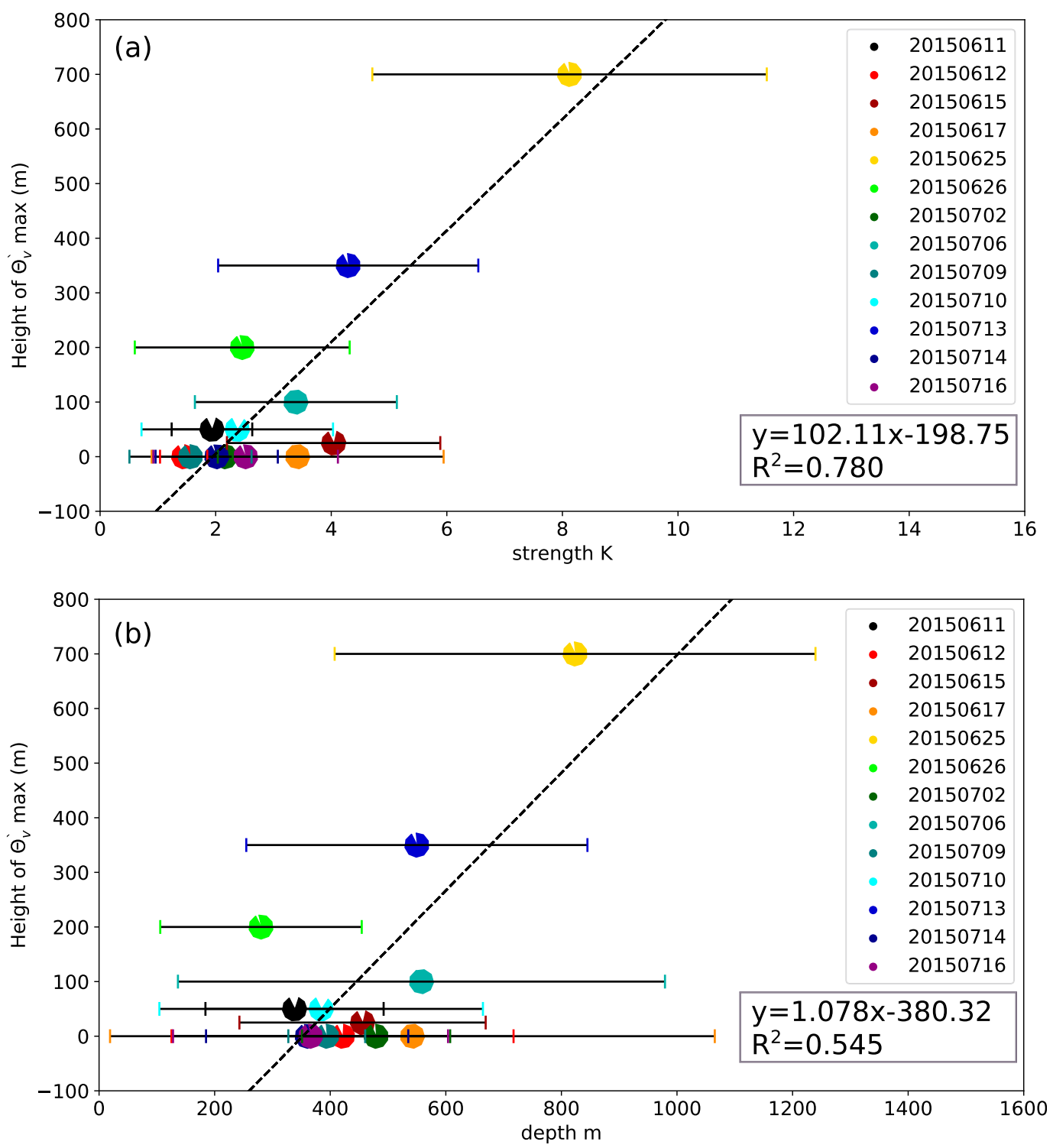

FIG. 10. Scatterplot of the height of greatest observed cooling (from Table 4) and the (a) strength (K) and (b) depth $(\mathrm{m})$ of the observed stable layer in preconvective soundings. Individual markers are pie charts that indicate the fraction of the preconvective soundings with an identifiable low-level stable layer (shaded). Bars represent one standard deviation.

nocturnal nature of these MCSs and evidence of an LLJ, around 30\% PECAN MCS soundings fell into this category.

A third category, termed "potentially neutral," thermodynamically resembled the previous category at low levels. Soundings in this category were generally taken on the cool side of a frontal boundary or after a wind shift, and so had either very weak or even northerly surface winds. Again, despite being postfrontal and nocturnal, around $30 \%$ of soundings fell into this category. Combined with the other potentially neutral category, over half of the PECAN MCS soundings did not have a $\theta_{e}$ maximum aloft.
Composite RAP analysis of the primary cases that make up the elevated instability cluster indicate stronger $850-\mathrm{hPa}$ southerly winds, a large moisture content that tends to increase to the south, and consequently more moisture advection across a larger, more continuous region than composites of the potentially neutral clusters. The orientation of the temperature gradient relative to the low-level winds in the elevated instability cluster is also more favorable for warm air advection.

The strength and depth of observed stable layers have a large amount of variability both between cases 
and within individual cases. Stable layers are not present in every sounding from every case, but the majority of soundings launched in each case did have some identifiable near-surface stable layer.

Characteristics of the observed postconvective region are highly variable from case to case (and even within a single case), but nearly every case had evidence of a cold pool. Observed average $\theta_{v}^{\prime}$ s ranged from nearly $-10 \mathrm{~K}$ to less than $-2 \mathrm{~K}$ and over depths from less than $150 \mathrm{~m}$ to over $4 \mathrm{~km}$. Across all cases, the average observed cold pool depth was just over $2 \mathrm{~km}$, and the average observed change in $\theta_{v}$ was $5-6 \mathrm{~K}$. In some cases, the maximum $\theta_{v}^{\prime}$ was observed near the surface, but in over half of the cases with density current observations, the cooling was maximized above the surface. The existence of a relationship between the height where the most cooling occurred and stable layer characteristics implies that low-level stability can modulate cold pool structure.

The primary findings of this work can be summarized as follows:

- A large number of PECAN MCS cases did not have an elevated layer of high $\theta_{e}$ air commonly associated with temperature and moisture advection by the low-level jet, despite evidence of at least a shallow southerly low-level wind maximum in many of the cases. These cases typically occurred earlier in the evening, but this profile can still exist well after dark. Critically, these cases had less moisture, less moisture advection, and less warm air advection than cases with $\theta_{e}$ maximized above the surface.

- Just under $50 \%$ of the PECAN MCS cases (30\% of soundings) fit into the classical conceptual model of an elevated $\theta_{e}$ maximum.

- There is a large amount of observed variability in the strength and depth of observed near-surface stable layers prior to the onset of convection.

- All cases with observations after the passage of convection had evidence of some surface cooling, the degree and depth of which varied substantially.

- There is a relationship between the level at which cooling is maximized and characteristics of the nocturnal stable layer. This has implications on understanding the structure of cold pools produced by nocturnal storms.

In past literature, several different mechanisms have been shown to be capable of maintaining MCSs in stable environments. The mechanism depends on a number of factors including the strength of the stable layer and vertical wind shear characteristics. Until relatively recently, nocturnal MCSs were generally thought to be decoupled from the boundary layer due to the stability of the boundary layer. However, the rather consistent presence of surface cold pools despite preconvective environmental stability observed in the PECAN MCS cases suggests that surface cold pools are likely much more common in nocturnal convection than previously thought-implying that many nocturnal MCSs may not actually be decoupled from the surface. This has a number of potential implications on a host of nocturnal MCS internal processes, environmental feedbacks, and so on.

At the same time, in every case, the majority of soundings observed a near-surface stable layer, but the large variability and potential importance brings to light some important questions. What factors influence the development of low-level stability? In the case of nocturnal cooling: low-level moisture, cloud cover, cloud type, vegetation, terrain, and other features with high spatial heterogeneity all play a role in the development of the nocturnal stable layer. On the cool side of a frontal boundary, the depth of the stable layer is related to the distance from the edge of the front, the slope of the frontal boundary, and perhaps more localized features as well. As discussed previously, convectively produced cold pools act to increase the stability of low levels (in fact, profiles that captured the passage of a cold pool prior to, or in the absence of convection looked remarkably similar to profiles whose low levels had likely been cooled radiatively). How does the development of a nocturnal stable layer vary spatially and temporally? Are there places that develop more consistent nocturnal stable layers than others? Does it take some regions longer to develop stable layers than others? Is the development of a low-level nocturnal stable layer influenced by any synoptic characteristics (other than front relative location)? Given the importance of understanding the interactions of MCSs with low-level stable layers, additional work into understanding the development of low-level stable layers (how/ when/where) in the nocturnal atmosphere would be of significant value.

Acknowledgments. This research is supported by NSF grants AGS-1359727 and AGS-1359709. The mobile upsonde systems that collected the radiosonde data used in this article were supported by the NSF Award AGS-1359726. A NOAA/Office of Atmospheric Research (OAR)/Office of Weather and Air Quality (AWAQ) award provided all mobile sounding expendables used by the CSU and two NSSL sounding vehicles during PECAN. Thanks to Sean Waugh and NOAA/National Severe Storms Laboratory (NSSL) for configuring and maintaining the CSU 

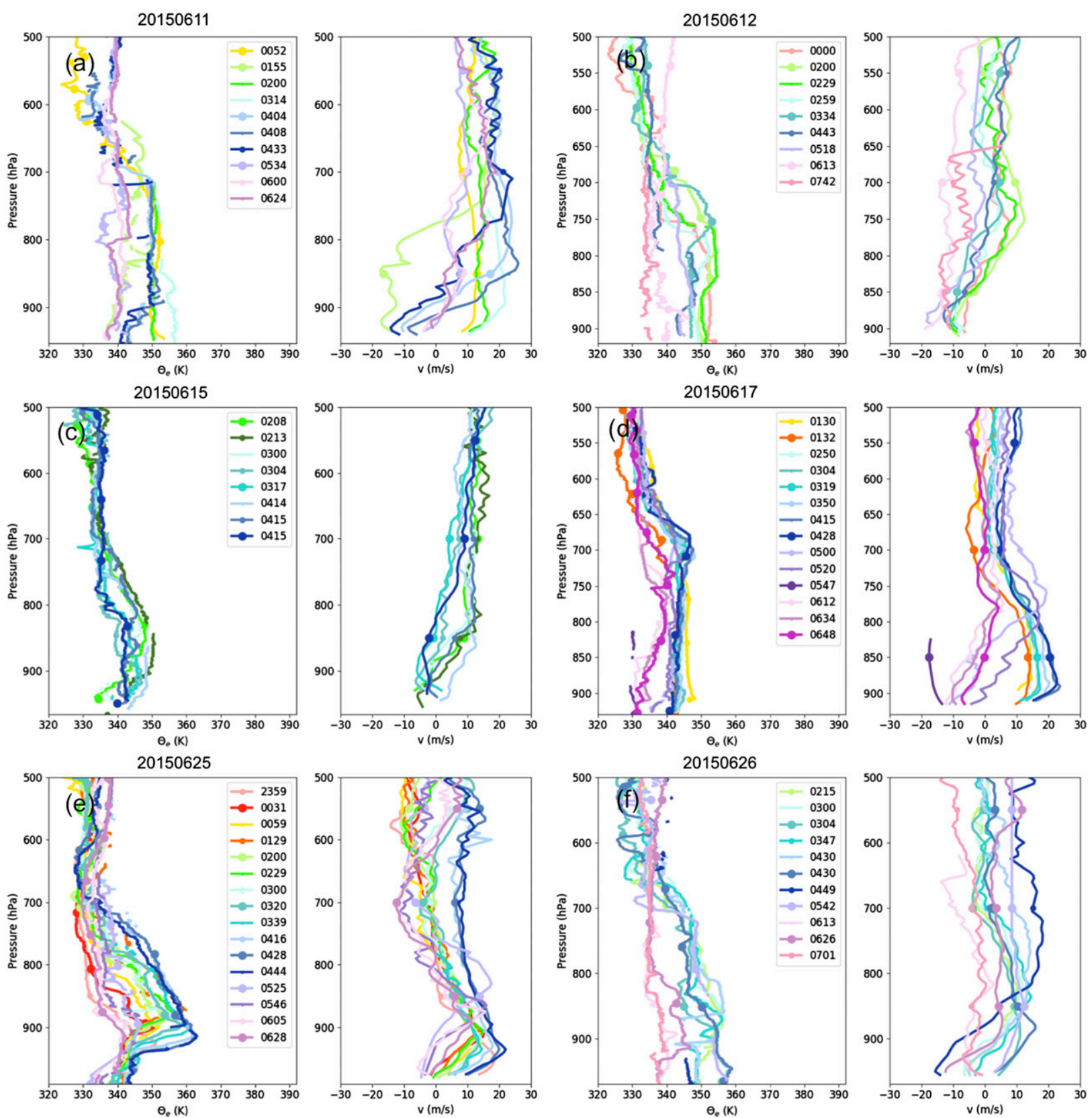

FIG. A1. All pre- and postconvective $\theta_{e}(\mathrm{~K})$ and meridional wind $\left(\mathrm{m} \mathrm{s}^{-1}\right)$ profiles from MG teams for (a) $11 \mathrm{Jun}$, (b) $12 \mathrm{Jun}$, (c) $15 \mathrm{Jun}$, (d) 17 Jun, (e) 25 Jun, and (f) 26 Jun. Each hour is represented by a color family with 00xx UTC profiles in reds and 04xx UTC profiles in blues. All MG profiles on 15 Jun observed postconvective regions.

and two NSSL mobile sounding vehicles. Thanks to Kevin Haghi for stable layer code and for critical, insightful discussions on stability and wave dynamics. Thanks to the Rutledge research group for sharing their archive of the NSSL MRMS data with us. Thanks to committee members Susan van den Heever, David Randall, and Richard Eykholt for feedback at various stages of this work. Thanks to members of the Schumacher research group past and present (Nathan Kelly, Sam Childs, John Peters, and especially Greg Herman and Erik Nielsen), Libby Barnes, Leah Grant, Peter Marinescu, and those who have given feedback at the PECAN science, AMS Mesoscale, and (CSU) Storms Super Group meetings. A special thank you also goes to the many PECAN participants for their dedication to seeing the sunrise before bedtime. Computing resources were provided by NCAR. 

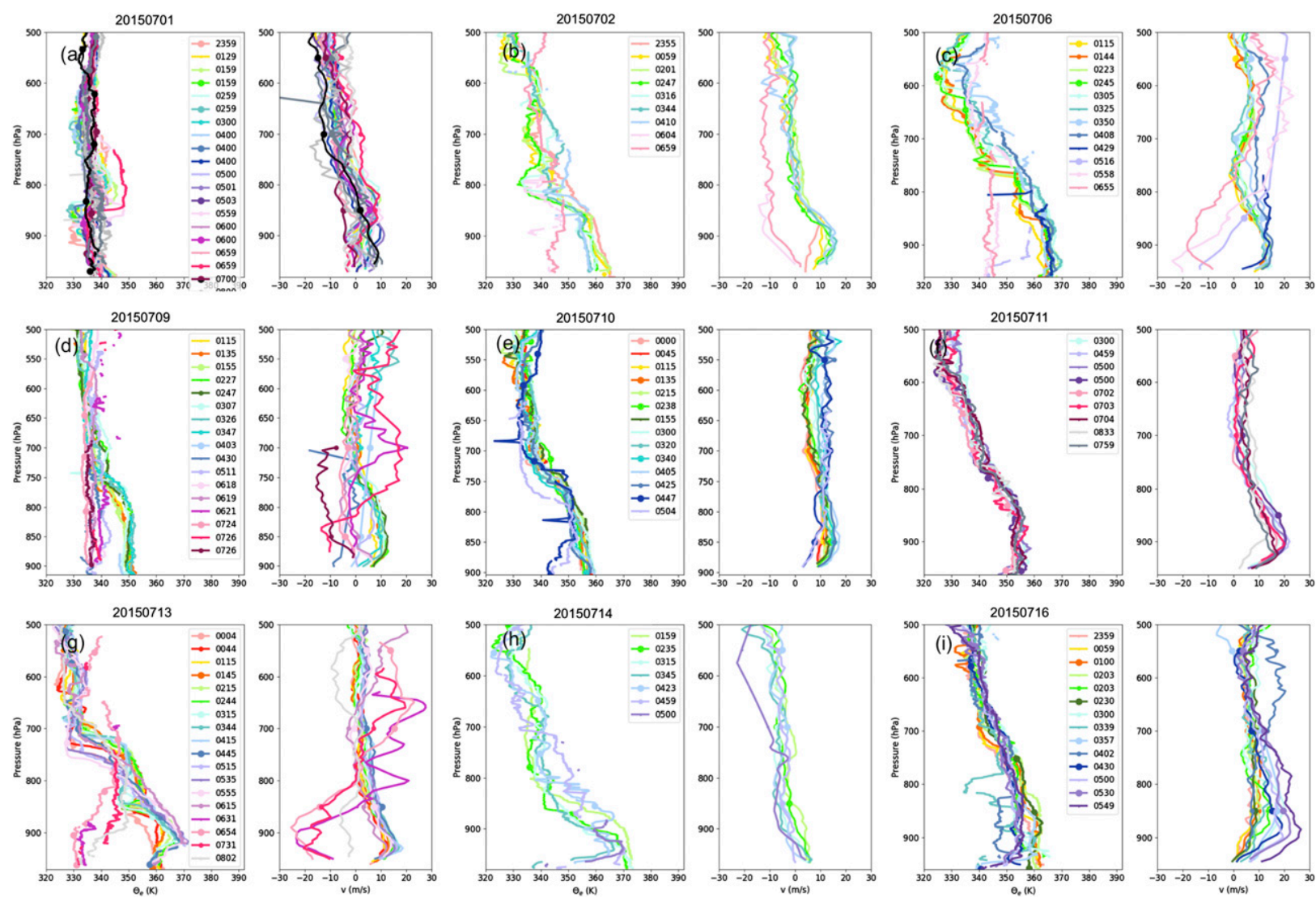

FIG. A2. All pre- and postconvective $\theta_{e}(\mathrm{~K})$ and meridional wind $\left(\mathrm{m} \mathrm{s}^{-1}\right)$ profiles from MG teams for (a) $1 \mathrm{Jul}$, (b) $2 \mathrm{Jul}$, (c) $6 \mathrm{Jul}$, (d) 9 $\mathrm{Jul}$, (e) $10 \mathrm{Jul}$, (f) $11 \mathrm{Jul}$, (g) $13 \mathrm{Jul}$, (h) $14 \mathrm{Jul}$, and (i) $16 \mathrm{Jul}$. Each hour is represented by a color family with 00xx UTC profiles in reds and 04xx UTC profiles in blues. All MG profiles on 11 Jul observed preconvective environments.

\section{APPENDIX A}

\section{PECAN Radiosonde Observations of MCS Environments}

Soundings launched by fixed and mobile teams documented the target MCS environments and their changes over time. Figures A1 and A2 show all of the observed thermodynamic (here represented as equivalent potential temperature or $\theta_{e}$ ) and meridional wind profiles from soundings launched by just the highly mobile MGs during June and July cases respectively. These teams were often placed at the same location for high-frequency ( $\sim 15 \mathrm{~min})$ launches as convection approached, but in a few cases teams were spread out for less frequent launches with greater spatial coverage (Figs. A1a,f, A2a,f,i). On 26 June, differences between the low-level $\theta_{e}$ at different MG locations are quite clear (Fig. A1f). In many cases, soundings documented a lowlevel southerly wind maximum that increased in magnitude with time, but the initial strength of this wind maximum and the change with time varied from case to case (Figs. A1, A2). In some cases $\theta_{e}$ changes substantially in the hours before the passage of convection (Figs. A1e, A2g). In other cases, almost no change is observed prior to the passage of the convective line (Figs. A1d, A2d). Similarly, in some cases the most unstable parcel (here, defined as the parcel with largest $\theta_{e}$ in the lowest $500 \mathrm{hPa}$ ) lies well above the surface (Figs. A1e, A2g), while in others the most unstable parcel appears surface based, even in soundings launched well after dark (Figs. A2b,d). These differences motivated much of the analysis in the first part of this paper.

There are also notable differences between $\theta_{e}$ profiles of observed postconvective environments not discussed elsewhere in this work. In some cases, the postconvective environment is potentially neutral through a large depth of the troposphere, and essentially all instability has been removed (Fig. A2d). In other cases, some potential instability remains, even a few hours after the passage of the leading line. Additionally, in some cases, MGs actually sampled the environment after the passage of a gust front, but before the arrival of the precipitation. This can usually be distinguished 

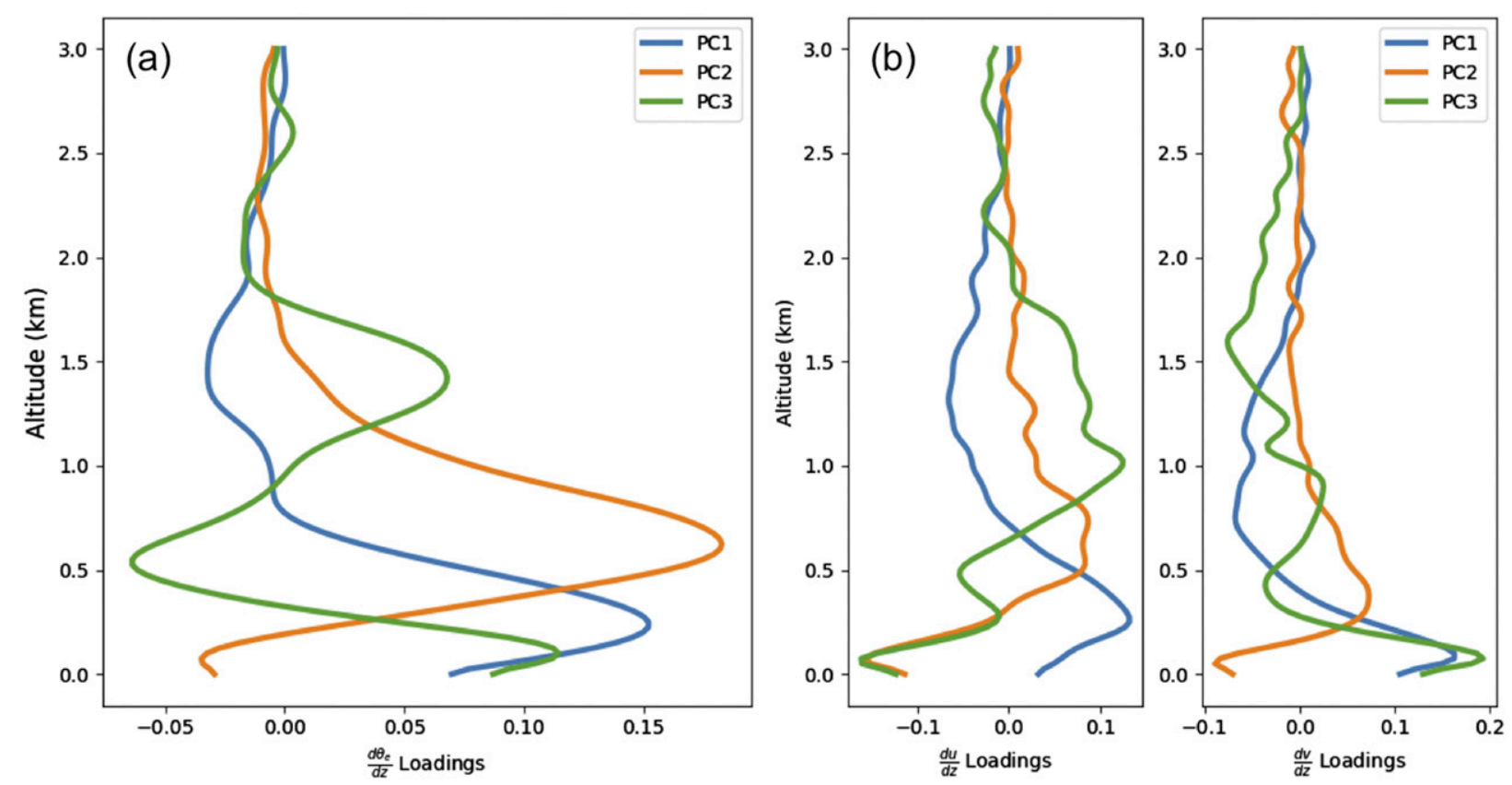

FIG. B1. PC loadings for (a) $d \theta_{e} / d z$, (b) $d u / d z$, and (c) $d v / d z$.

by profiles of $\theta_{e}$ that are similar to preconvective profiles everywhere but at the lowest levels where they tend to have a sharp increase with height (e.g., Fig. A2e). This is often accompanied by a decrease in the low-level meridional winds, even becoming negative in some cases (e.g., Fig. A2c). At least two soundings launched by MG teams into this region made it into the storm's updraft, and have unique thermodynamic profiles [0516 UTC (Fig. A2c) and 0654 UTC (Fig. A2c)].

\section{APPENDIX B}

\section{PCA and Cluster Algorithm Details}

\section{a. Principal component analysis}

North et al. (1982) argue that the degree of confidence in a principal component or PC is related to the degree of separation between the eigenvalues (or variance explained). The equation

$$
\Delta \lambda=\lambda \sqrt{\frac{2}{N^{*}}}
$$

where $\lambda$ is the eigenvalue $\Delta \lambda$ and $N^{*}$ is the degrees of freedom can be used to identify the $95 \%$ confidence interval bounds of the eigenvalues. In this dataset, the selection of $N^{*}$ was determined to be between 180 and 360 using 3 variables, 15 cases, approximately $8 \mathrm{~h}$ of launches per case, and assuming that the environment changes enough every $1-2 \mathrm{~h}$ to be independent. Calculations of $\Delta \lambda$ were not very sensitive to $N^{*}$ values in this range. Two breaks between eigenvalue confidence intervals appear between the first and second and the third and fourth eigenvalues. Because the first PC only explained about $18 \%$ of the variance, and based on differences in the PC loadings (Fig. B1), the first 3 PCs were retained.

Plotted PCs show $d \theta_{e} / d z, d u / d z$, and $d v / d z$ since those were the input variables to the PCA (Fig. B1). The absolute sign of the PC loadings can be either positive or negative (i.e., the profile can be reflected about the $x=0$ ), but the relative signs of the loadings for each PC are important. PC1 and 3 have been flipped to make relative loadings most relevant to this dataset. $d \theta_{e} / d z$ of $\mathrm{PC} 1$ is positive near the surface, increases to a maximum near $250 \mathrm{~m}$, decreases to a slightly negative value and then becomes nearly constant. This is like having an increase in $\theta_{e}$ in the layer below around $500 \mathrm{~m}$, and a shift to a fairly constant negative slope, just like many profiles in the 'elevated instability' cluster. ${ }^{\mathrm{B} 1}$ Similarly, the wind loadings for PC1 fit the elevated instability cluster. $d u / d z$ is positive until just above $500 \mathrm{~m}$ and becomes weakly negative thereafter, capturing the increase in westerly winds to about

\footnotetext{
${ }^{\mathrm{B} 1}$ Individual clusters are explicitly introduced and discussed in section 4 .
} 
$500 \mathrm{~m} . d v / d z$ is also positive until just below $500 \mathrm{~m}$, similar to the positive slope seen in $\mathrm{v}$ for both elevated instability and potentially neutral + jet winds. In $\mathrm{PC} 2, d \theta_{e} / d z$ is positive from just above the surface to around $1.5 \mathrm{~km}$ where it becomes weakly negative with an decrease in both $u$ and $v$ very near the surface, most closely resembling profiles from 12 June. In PC3, $d \theta_{e} / d z$ describes $\theta_{e}$ profiles that have slight potential stability near the surface, and then oscillate slightly between potentially unstable and potentially stable below $2 \mathrm{~km}$. Winds in this PC fit most closely with the potential neutral cluster where near-surface slopes of $u$ and $v$ have opposite signs. The two potentially neutral clusters seem to be made up of a combination of PC2 and PC3 where $d \theta_{e} / d z$ in the two PCs has opposite signs, zonal winds have an easterly surface component and meridional winds are different between clusters.

\section{b. Shared nearest neighbors (SNN) clustering}

SNN defines similarity between a pair of points based on their shared nearest neighbors. If two points have the same neighbor, they are closer/more similar (Ertoz et al. 2002). To apply this, nearest neighbors were first identified. Unlike other methods where this distance is retained, if the points were identified as a neighbor, they were given a value of one, so that density is redefined based on the number of shared neighbors. In this way, points that have many other points in common become the core of the clusters. Once density is redefined, DBSCAN can be used to filter out points that do not have many shared neighbors, and will cluster groups based on how many neighbors they share. While DBSCAN is a cluster algorithm in and of itself, it is also used in this application of SSN. DBSCAN has two parameters: one is related to the acceptable multidimensional physical distance of points in a cluster $(\varepsilon)$, the other is the minimum number of neighbors a point must have to be included in a cluster (minPts). In this method, a rather large number of minimum points, 34 , can be used to create physically sensible clusters for this dataset. The Manhattan distance metric was chosen so that if two points are both neighbors or are not both neighbors with the same third point, they do not contribute to the distance of the cluster. If one of the points is a neighbor but the other is not, then they do not share the neighbor and the distance of the cluster increases. Since $\varepsilon$ is the physical distance of points permitted in the cluster, here, it means that the maximum number of unshared nearest neighbors is also 34. In other words, half of the nearest neighbors between any two soundings in a cluster must be shared.

\section{REFERENCES}

Alfaro, D. A., and M. C. Coniglio, 2018: Discrimination of mature and dissipating severe-wind-producing MCSs with layerlifting indices. Wea. Forecasting, 33, 3-21, https://doi.org/ 10.1175/WAF-D-17-0088.1.

Augustine, J. A., and F. Caracena, 1994: Lower-tropospheric precursors to nocturnal MCS development over the central United States. Wea. Forecasting, 9, 116-135, https://doi.org/ 10.1175/1520-0434(1994)009<0116:LTPTNM>2.0.CO;2.

Benjamin, S. G., and Coauthors, 2016: A North American hourly assimilation and model forecast cycle: The Rapid Refresh. Mon. Wea. Rev., 144, 1669-1694, https://doi.org/10.1175/ MWR-D-15-0242.1.

Billings, J. M., and M. D. Parker, 2012: Evolution and maintenance of the 22-23 June 2003 nocturnal convection during BAMEX. Wea. Forecasting, 27, 279-300, https://doi.org/10.1175/WAFD-11-00056.1.

Bryan, G. H., and J. M. Fritsch, 2000: Moist absolute instability: The sixth static stability state. Bull. Amer. Meteor. Soc., 81, 1207-1230, https://doi.org/10.1175/1520-0477(2000)081<1287: MAITSS $>2.3 . \mathrm{CO} ; 2$.

Carbone, R. E., J. W. Conway, N. A. Crook, and M. W. Moncrieff, 1990: The generation and propagation of a nocturnal squall line. Part I: Observations and implications for mesoscale predictability. Mon. Wea. Rev., 118, 26-49, https://doi.org/10.1175/ 1520-0493(1990)118<0026:TGAPOA > 2.0.CO;2.

— J. D. Tuttle, D. A. Ahijevych, and S. B. Trier, 2002: Inferences of predictability associated with warm season precipitation episodes. J. Atmos. Sci., 59, 2033-2056, https://doi.org/10.1175/ 1520-0469(2002)059<2033:IOPAWW>2.0.CO;2.

Clark, R., 2016: FP3 Ellis, KS radiosonde data, version 2.0. UCAR/ NCAR-Earth Observing Laboratory, accessed 22 September 2016, https://doi.org/10.5065/D6GM85DZ.

Clark, A. J., W. A. Gallus Jr., and T.-C. Chen, 2007: Comparison of the diurnal precipitation cycle in convection-resolving and non-convection-resolving mesoscale models. Mon. Wea. Rev., 135, 3456-3473, https://doi.org/10.1175/MWR3467.1.

Corfidi, S. F., S. J. Corfidi, and D. M. Schultz, 2008: Elevated convection and castellanus: Ambiguities, significance, and questions. Wea. Forecasting, 23, 1280-1303, https://doi.org/ 10.1175/2008WAF2222118.1.

Correia, J., Jr., and R. W. Arritt, 2008: Thermodynamic properties of mesoscale convective systems observed during BAMEX. Mon. Wea. Rev., 136, 4242-4271, https://doi.org/10.1175/ 2008MWR2284.1.

Crook, N. A., 1988: Trapping of low-level gravity waves. J. Atmos. Sci., 45, 1533-1541, https://doi.org/10.1175/1520-0469(1988)045<1533: TOLLIG $>2.0 . \mathrm{CO} ; 2$.

—, and M. W. Moncrieff, 1988: The effect of large-scale convergence on the generation and maintenance of deep moist convection. J. Atmos. Sci., 45, 3606-3624, https://doi.org/10.1175/ 1520-0469(1988)045<3606:TEOLSC $>2.0$. CO;2.

Cunning, J. B., 1986: The Oklahoma-Kansas Preliminary Regional Experiment for STORM-Central. Bull. Amer. Meteor. Soc., 67, 1478-1486, https://doi.org/10.1175/1520-0477(1986) 067<1478:TOKPRE $>2.0 . \mathrm{CO} ; 2$.

Davis, C., and Coauthors, 2004: The Bow Echo and MCV Experiment: Observations and opportunities. Bull. Amer. Meteor. Soc., 85, 1075-1094, https://doi.org/10.1175/BAMS-85-8-1075.

Davis, C. A., K. W. Manning, R. E. Carbone, S. B. Trier, and J. D. Tuttle, 2003: Coherence of warm-season continental rainfall in numerical weather prediction models. Mon. Wea. Rev., 131, 
2667-2679, https://doi.org/10.1175/1520-0493(2003)131<2667: COWCRI $>2.0 . \mathrm{CO} ; 2$.

Ertoz, L., M. Steinbach, and V. Kumar, 2002: A new shared nearest neighbor clustering algorithm and its applications. Workshop on Clustering High Dimensional Data and Its Applications at Second SIAM Int. Conf. on Data Mining, Arlington, VA, AHPCRC and University of Illinois at Chicago, 105-115.

Ester, M., H.-P. Kriegel, J. Sander, and X. Xu, 1996: A density-based algorithm for discovering clusters in large spatial databases with noise. KDD'96 Proc. Second International Conference on Knowledge Discovery and Data Mining, Portland, OR, Association for the Advancement of Artificial Intelligence, 226-231.

French, A. J., and M. D. Parker, 2008: The initiation and evolution of multiple modes of convection within a meso-alphascale region. Wea. Forecasting, 23, 1221-1252, https://doi.org/ 10.1175/2008WAF2222136.1.

- , and 2010: The response of simulated nocturnal convective systems to a developing low-level jet. J. Atmos. Sci., 67, 3384-3408, https://doi.org/10.1175/2010JAS3329.1.

Fritsch, J. M., and G. S. Forbes, 2001: Mesoscale convective systems. Severe Convective Storms, Meteor. Monogr., No. 50, Amer. Meteor. Soc., 323-357.

— , R. J. Kane, and C. R. Chelius, 1986: The contribution of mesoscale convective weather systems to the warm-season precipitation in the United States. J. Climate Appl. Meteor., 25, 1333-1345, https://doi.org/10.1175/1520-0450(1986)025<1333: TCOMCW $>2.0 . \mathrm{CO} ; 2$.

Geerts, B., and Coauthors, 2017: The 2015 Plains Elevated Convection At Night (PECAN) field project. Bull. Amer. Meteor. Soc., 98, 767-786, https://doi.org/10.1175/BAMS-D-15-00257.1.

Glickman, T., Ed., 2000: Glossary of Meteorology. 2nd ed. Amer. Meteor. Soc., 855 pp., http://glossary.ametsoc.org/.

Haertel, P. T., R. H. Johnson, and S. N. Tulich, 2001: Some simple simulations of thunderstorm outflows. J. Atmos. Sci., 58, 504-516, https://doi.org/10.1175/1520-0469(2001) $058<0504:$ SSSOTO $>2.0$. CO 2 .

Haghi, K. R., D. B. Parsons, and A. Shapiro, 2017: Bores observed during IHOP_2002: The relationship of bores to the nocturnal environment. Mon. Wea. Rev., 145, 3929-3946, https://doi.org/ 10.1175/MWR-D-16-0415.1.

Herman, G. R., and R. S. Schumacher, 2018: Money doesn't grow on trees, but forecasts do: Forecasting extreme precipitation with random forests. Mon. Wea. Rev., 146, 1571-1600, https:// doi.org/10.1175/MWR-D-17-0250.1.

Hewson, E. W., 1937: The application of wet-bulb potential temperature to air mass analysis. III. Rainfall in depressions. Quart. J. Roy. Meteor. Soc., 63, 323-338, https://doi.org/10.1002/ qj. 49706327105.

Holdridge, D., and D. Turner, 2015: FP6 Hesston, KS radiosonde data, version 1.0. UCAR/NCAR-Earth Observing Laboratory, accessed 22 September 2016, https://doi.org/10.5065/D6765CD0.

Houze, R. A., Jr., 2004: Mesoscale convective systems. Rev. Geophys., 42, RG4003, https://doi.org/10.1029/2004RG000150.

Jirak, I. L., W. R. Cotton, and R. L. McAnelly, 2003: Satellite and radar survey of mesoscale convective system development. Mon. Wea. Rev., 131, 2428-2449, https://doi.org/10.1175/15200493(2003)131<2428:SARSOM > 2.0.CO;2.

Johnson, A., and X. Wang, 2013: Object-based evaluation of a storm-scale ensemble during the 2009 NOAA Hazardous Weather Testbed Spring Experiment. Mon. Wea. Rev., 141, 1079-1098, https://doi.org/10.1175/MWR-D-12-00140.1.

,,-- F. Kong, and M. Xue, 2013: Object-based evaluation of the impact of horizontal grid spacing on convection-allowing forecasts. Mon. Wea. Rev., 141, 3413-3425, https://doi.org/ 10.1175/MWR-D-13-00027.1.

Klein, P. M., D. D. Turner, E. N. Smith, and J. Gebauer, 2016: Mobile PISA 1 OU/NSSL CLAMPS radiosonde data, version 1.0. UCAR/NCAR-Earth Observing Laboratory, accessed 22 September 2016, https://doi.org/10.5065/D6416VDH.

Knupp, K., 2015: Mobile PISA 2 UAH MIPS Radiosonde Data, version 1.0. UCAR/NCAR-Earth Observing Laboratory, accessed 22 September 2016, https://doi.org/10.5065/ D6MC8X3V.

Laing, A. G., and J. M. Fritsch, 2000: The large scale environments of the global populations of mesoscale convective complexes. Mon. Wea. Rev., 128, 2756-2776, https://doi.org/ 10.1175/1520-0493(2000)128<2756:TLSEOT>2.0.CO;2.

Maddox, R. A., 1980: Mesoscale convective complexes. Bull. Amer. Meteor. Soc., 61, 1374-1387, https://doi.org/10.1175/ 1520-0477(1980)061<1374:MCC >2.0.CO;2.

, 1983: Large scale meteorological conditions associated with midlatitude mesoscale convective complexes. Mon. Wea. Rev., 111, 1475-1493, https://doi.org/10.1175/1520-0493(1983) $111<1475$ :LSMCAW $>2.0$. CO;2.

_ L. R. Hoxit, C. F. Chappell, and F. Caracena, 1978: Comparison of meteorological aspects of the Big Thompson and Rapid City flash floods. Mon. Wea. Rev., 106, 375-389, https://doi.org/ 10.1175/1520-0493(1978)106<0375:COMAOT >2.0.CO;2.

Marsham, J. H., K. A. Browning, J. C. Nicol, D. J. Parker, E. G. Norton, A. M. Blyth, U. Corsmeier, and F. M. Perry, 2010: Multisensor observations of a wave beneath an impacting rear-inflow jet in an elevated mesoscale convective system. Quart. J. Roy. Meteor. Soc., 136, 1788-1812, https://doi.org/10.1002/qj.669.

Moncrieff, M. W., 1992: Organized convective systems: Archetypal dynamical models, mass and momentum flux theory, and parameterization. Quart. J. Roy. Meteor. Soc., 118, 819-850, https://doi.org/10.1002/qj.49711850703.

Moore, J. T., F. H. Glass, C. E. Graves, S. M. Rochette, and M. J. Singer, 2003: The environment of warm-season elevated thunderstorms associated with heavy rainfall over the central United States. Wea. Forecasting, 18, 861-878, https://doi.org/ 10.1175/1520-0434(2003)018<0861:TEOWET>2.0.CO;2.

North, G. R., T. L. Bell, R. F. Cahalan, and F. J. Moeng, 1982: Sampling errors in the estimation of empirical orthogonal functions. Mon. Wea. Rev., 110, 699-706, https://doi.org/10.1175/ 1520-0493(1982)110<0699:SEITEO > 2.0.CO;2.

Parker, M. D., 2008: Response of simulated squall lines to low-level cooling. J. Atmos. Sci., 65, 1323-1341, https://doi.org/10.1175/ 2007JAS2507.1.

— , and R. H. Johnson, 2000: Organizational modes of midlatitude mesoscale convective systems. Mon. Wea. Rev., 128, 3413-3436, https://doi.org/10.1175/1520-0493(2001)129<3413: OMOMMC $>2.0 . \mathrm{CO} ; 2$.

Peters, J. M., and R. S. Schumacher, 2014: Objective categorization of heavy-rain-producing MCS synoptic types by rotated principal component analysis. Mon. Wea. Rev., 142, 1716-1737, https://doi.org/10.1175/MWR-D-13-00295.1.

, and _ 2015: Mechanisms for organization and echo training in a flash-flood-producing mesoscale convective system. Mon. Wea. Rev., 143, 1058-1085, https://doi.org/10.1175/ MWR-D-14-00070.1.

_, E. R. Nielsen, M. D. Parker, S. M. Hitchcock, and R. S. Schumacher, 2017: The impact of low-level moisture errors on model forecasts of an MCS observed during PECAN. Mon. Wea. Rev., 145, 3599-3624, https://doi.org/10.1175/ MWR-D-16-0296.1. 
Raymond, D. J., and R. Rotunno, 1989: Response of a stably stratified flow to cooling. J. Atmos. Sci., 46, 2830-2837, https://doi.org/ 10.1175/1520-0469(1989)046<2830:ROASSF $>2.0$. CO;2.

Rossby, C.-G., 1932: Thermodynamics Applied to Air Mass Analysis. Massachusetts Institute of Technology, $48 \mathrm{pp}$.

Rottman, J. W., and J. E. Simpson, 1989: The formation of internal bores in the atmosphere: A laboratory model. Quart. J. Roy. Meteor. Soc., 115, 941-963, https://doi.org/10.1002/ qj. 49711548809 .

Schultz, D. M., P. N. Schumacher, and C. A. Doswell III, 2000: The intricacies of instabilities. Mon. Wea. Rev., 128, 4143-4148, https:// doi.org/10.1175/1520-0493(2000)129<4143:TIOI>2.0.CO;2.

Schumacher, R. S., 2009: Mechanisms for quasi-stationary behavior in simulated heavy-rain-producing convective systems. J. Atmos. Sci., 66, 1543-1568, https://doi.org/10.1175/2008JAS2856.1.

_, and R. H. Johnson, 2005: Organization and environmental properties of extreme-rain-producing mesoscale convective systems. Mon. Wea. Rev., 133, 961-976, https://doi.org/10.1175/MWR2899.1.

Trier, S. B., and D. B. Parsons, 1993: Evolution of environmental conditions preceding the development of a nocturnal mesoscale convective complex. Mon. Wea. Rev., 121, 1078-1098, https://doi.org/10.1175/1520-0493(1993)121<1078: EOECPT $>2.0 . \mathrm{CO} ; 2$.

, C. A. Davis, and J. D. Tuttle, 2000: Long-lived mesoconvective vortices and their environment. Part I: Observations from the central United States during the 1998 warm season. Mon. Wea. Rev., 128, 3376-3395, https://doi.org/10.1175/1520-0493(2000) 128<3376:LLMVAT>2.0.CO;2.

,,- D. A. Ahijevych, M. L. Weisman, and G. H. Bryan, 2006: Mechanisms supporting long-lived episodes of propagating nocturnal convection within a 7-day WRF model simulation. J. Atmos. Sci., 63, 2437-2461, https://doi.org/10.1175/JAS3768.1.

_ J. H. Marsham, C. A. Davis, and D. A. Ahijevych, 2011: Numerical simulations of the postsunrise reorganization of a nocturnal mesoscale convective system during 13 June IHOP_2002. J. Atmos. Sci., 68, 2988-3011, https://doi.org/ 10.1175/JAS-D-11-0112.1.

UCAR/NCAR-Earth Observing Laboratory, 2015: FP1 ARM Central Facility radiosonde data, version 1.0. UCAR/NCAREarth Observing Laboratory, accessed 22 September 2016, http://data.eol.ucar.edu/dataset/485.021.

, 2016a: National Weather Service High Resolution Radiosonde Data (EOL Format), version 1.0. UCAR/NCAR-Earth
Observing Laboratory, accessed 22 September 2016, https:// doi.org/10.5065/D6FT8J8G.

_ 2016b: FP4 NCAR/EOL QC Soundings, version 2.0. UCAR/ NCAR-Earth Observing Laboratory, accessed 22 September 2016, https://doi.org/10.5065/D63776XH.

_ 2016c: FP5 NCAR/EOL QC Soundings, version 2.0. UCAR/ NCAR-Earth Observing Laboratory, accessed 22 September 2016, https://doi.org/10.5065/D6ZG6QF7.

_ 2016d: MP4 NCAR/EOL QC Soundings, version 2.0. UCAR/ NCAR-Earth Observing Laboratory, accessed 22 September 2016, https://doi.org/10.5065/D6707ZNV.

Vermeesch, K., 2016: FP2 Greensburg, KS radiosonde data, version 1.0. UCAR/NCAR-Earth Observing Laboratory, accessed 22 September 2016, https://doi.org/10.5065/ D6FQ9TPH.

Wagner, T. J., E. Olsen, N. Smith, and W. Feltz, 2016: Mobile PISA 3 UW/SSEC SPARC Radiosonde Data, version 2.0. UCAR/ NCAR-Earth Observing Laboratory, accessed 22 September 2016, https://doi.org/10.5065/D6VH5M7B.

Wallace, J. M., 1975: Diurnal variations in precipitation and thunderstorm frequency over the conterminous United States. Mon. Wea. Rev., 103, 406-419, https://doi.org/10.1175/15200493(1975)103<0406:DVIPAT>2.0.CO;2.

Weisman, M. L., and Coauthors, 2015: The Mesoscale Predictability Experiment (MPEX). Bull. Amer. Meteor. Soc., 96, 2127-2149, https://doi.org/10.1175/BAMS-D-13-00281.1.

Wilson, J. W., and R. D. Roberts, 2006: Summary of convective storm initiation and evolution during IHOP: Observational and modeling perspective. Mon. Wea. Rev., 134, 23-47, https:// doi.org/10.1175/MWR3069.1.

Wurman, J., D. Dowell, Y. Richardson, P. Markowski, E. Rasmussen, D. Burgess, L. Wicker, and H. B. Bluestein, 2012: The second verification of the origins of rotation in tornadoes experiment: VORTEX2. Bull. Amer. Meteor. Soc., 93, 1147-1170, https://doi.org/10.1175/BAMS-D-11-00010.1.

Zhang, J., and Coauthors, 2016: Multi-Radar Multi-Sensor (MRMS) quantitative precipitation estimation: Initial operating capabilities. Bull. Amer. Meteor. Soc., 97, 621-638, https://doi.org/10.1175/BAMS-D-14-00174.1.

Ziegler, C. L., M. C. Coniglio, M. D. Parker, and R. S. Schumacher, 2016: CSU/NCSU/NSSL MGAUS Radiosonde Data, version 3.0. UCAR/NCAR-Earth Observing Laboratory, accessed 22 September 2016, https://doi.org/10.5065/D6W66HXN. 